5.

Derecho ambiental 

Revista de Derecho

de la Pontificia Universidad Católica de Valparaíso

XXXVI (Valparaíso, Chile, 2011, $1^{\text {er }}$ Semestre)

[pp. $281-323]$

\section{LA PARTICIPACIÓN CIUDADANA EN EL PROCEDIMIENTO DE EVALUACIÓN DE IMPACTO AMBIENTAL Y LAS REFORMAS INTRODUCIDAS POR LA LEY No $20.417^{*}$}

["Citizen Participation in the Environmental Impact Assessment Procedure and Legal Modifications Introduced by Act Nr 20.417”]

\section{Camilo Mirosevic Verdugo**}

\begin{abstract}
RESUMEN
La participación ciudadana constituye uno de los principios que inspiran el moderno Derecho ambiental, dado los especiales caracteres del entorno. En el ordenamiento chileno, la legislación ambiental reconoce diversos espacios de intervención de la ciudadanía, uno de ellos, el procedimiento de evaluación de impacto ambiental. El objeto del traba-
\end{abstract}

\begin{abstract}
Citizen participation is one of the principles of modern Environmental Law, because of the special characteristics of the environment. In Chilean Law, the environmental regulation considers different spaces of citizen participation, one of them, in the environmental impact assessment procedure.

In this framework, the target of this
\end{abstract}

*Abreviaturas: CONAMA = Comisión Nacional del Medio Ambiente; CORE = Consejo Regional; COREMA = Comisión Regional del Medio Ambiente; "dia." = "declaración de impacto ambiental"; "eia." = "estudio de impacto ambiental"; LAIP. = Ley No 20.285: sobre Acceso a la información pública; LBGAE. = Ley No 18.575: Orgánica constitucional de bases generales de la Administración del Estado; LBGMA. = Ley No 19.300: sobre Bases generales del medio ambiente; LBPA.ñ = Ley No 19.880: de Bases de procedimientos administrativos; "rca." = "resolución de calificación ambiental"; RSEIA. = Decreto supremo No 95, de 2001, del Ministerio Secretaría General de la Presidencia: Reglamento del sistema de evaluación de impacto ambiental; SEA = Servicio de Evaluación Ambiental; "seia" = sistema de evaluación de impacto ambiental.

** Ayudante de Legislación Ambiental en la Facultad de Agronomía de la Pontificia Universidad Católica de Valparaíso. Dirección postal: Huérfanos 1055, oficina 308, Santiago. Correo electrónico: cmirosevic@mirosevic-asociados.cl El autor agradece los valiosos comentarios al presente trabajo de José Ortiz Tapia y Bernardo Zentilli van Kilsdonk. 
jo es presentar y analizar las instancias de participación en ese procedimiento administrativo, en particular, aquellas creadas a partir de las modificaciones que introdujo la Ley $\mathrm{N}^{\circ} 20.417$, incluyendo en el estudio las deficiencias que en la materia se observan.

\section{Palabras Clave}

Participación ciudadana - Participación ambiental - Sistema de evaluación de impacto ambiental. paper is to present and analyse the participation spaces in this administrative procedure, especially since the legal modifications introduced by Act No 20.417, and also the deficiencies in this matter.

KEYWORDS

Citizen participation - Environmental participation- Environmental impact assessment system.

[RECIBIDo el 8 de marzo y ACEPTADo el 10 de junio de 2011].

\section{INTRODUCCIÓN}

Probablemente uno de los ámbitos donde tradicionalmente se ha asignado mayor relevancia a la participación de la ciudadanía sea en materia ambiental. Esto se explica, desde una primera aproximación general, debido al carácter social del ambiente, a la universalidad del daño al entorno y a la titularidad común de los elementos que lo componen (considerados como "public good" y "common pool resources"). Las intensas modalidades de participación que se consultan en el ordenamiento ambiental obedecen también a que la regulación del entorno incide fuertemente en la esfera jurídica de los particulares, de modo que se les atribuye a éstos amplias posibilidades de intervención en las decisiones de la Administración. Del mismo modo, la participación constituye una concreción del principio de cooperación de los ciudadanos con la Administración, puesto que en ocasiones la acción de ésta resulta insuficiente para la tutela efectiva del ambiente, de modo que a la ciudadanía corresponde un activo rol de colaboración en dicha función de interés público ${ }^{1}$. Por ello se señala que la complejidad de los problemas ambientales demanda la concertación de esfuerzos de los diferentes interesados en aras de un objetivo común ${ }^{2}$. Desde esta óptica, para algunos autores la participación ciudadana presenta carácter dual, esto es, constituye tanto un derecho como un deber de la ciudadanía ${ }^{3}$.

${ }^{1}$ Dieguez, Marcia - Cureau, Sandra, Direito ambiental (Rio de Janeiro,Elsevier 2008), p. 137.

${ }^{2}$ Bell, Stuart y MacGillivray, Dondald, Environmental Law (Oxford, Oxford University Press 2006), p. 318.

${ }^{3}$ En tal sentido se pronuncia: Andaluz, Carlos, Manual de Derecho ambiental (Lima, Proterra 2006), pp. 543 ss. 
Las explicaciones más recientes sobre el rol de la participación en este ámbito ahondan en el concepto de justicia ambiental en su dimensión de distribución equitativa de las cargas o externalidades ambientales. Éstas corresponden a los efectos o impactos ambientales no deseados sobre un grupo de la población, producto de la realización de un proyecto o actividad. Como explica la profesora Dominique Hervé, el llamado problema ambiental se caracteriza precisamente por generar externalidades que deben ser distribuidas en la sociedad, de modo que la participación de la ciudadanía se encuentra directamente relacionada con las cargas ambientales a que se verá sometida con ocasión del desarrollo de un determinado proyectó ${ }^{4}$.

Doctrinalmente se ha definido la participación ciudadana en este ámbito como el conjunto de directrices, principios y normas dispuestas por la ley y la autoridad competente, que permiten a las personas naturales y jurídicas $\mathrm{y}$ a las organizaciones sociales y comunitarias afectadas o interesadas en alguna forma por distintos eventos de relevancia ambiental, ser incorporadas formalmente al proceso de decisiones que lleva a la adopción de políticas y medidas de carácter medioambiental, a la autorización de actividades que importan un compromiso ambiental, a la dictación de las regulaciones pertinentes, y a la resolución de los conflictos que se presenten 5 . A pesar que el concepto parece restringir la participación a aquellos que resulten afectados por las decisiones de la Autoridad ambiental, es decir, en cuanto mecanismo de defensa de intereses, la participación en esta materia no debe circunscribirse exclusivamente a los afectados con las decisiones, sino que puede operar también como mecanismo que apunte al interés general de la colectividad y no sólo de determinados sectores.

Por las razones expuestas, actualmente la participación ciudadana ocupa un lugar destacado en el Derecho internacional del medio ambiente y, por ende, ha sido reconocida en cuanto tal por diversos instrumentos internacionales multilaterales ${ }^{6}$ y declaraciones como la Carta Mundial de la Naturaleza

${ }^{4}$ Hervé, Dominique, El desarrollo sostenible y la justicia ambiental en la Ley 19.300 y en el Proyecto de reforma a la institucionalidad ambiental, en HERvé, Dominique - Guiloff, Matías - PÉREz, Raimundo (editores), Reforma a la institucionalidad ambiental. Antecedentes y fundamentos (Santiago, Universidad Diego Portales 2010), pp. 271 y 281.

${ }^{5}$ Moreno, Carlos, Participación ciudadana en la Ley No 19.300, sobre Bases generales del medio ambiente (Santiago, LexisNexis 2004), p. 47.

${ }^{6}$ Probablemente el instrumento internacional más desarrollado en la materia sea el "2Convenio de Aarhus" de 1998 sobre el Acceso a la información, la participación del público en la toma de decisiones y el acceso a la justicia en asuntos ambientales. Su artículo 1 establece como objetivo del Convenio: "A fin de contribuir a proteger el derecho de cada persona, de las generaciones presentes y futuras, a vivir en un medio ambiente quepermita garantizar su salud y su bienestar, cada Parte garantizará los derechos de acceso a la 
aprobada por la ONU en 1982 (puntos $23^{\circ}$ y $24^{\circ}$ ), la "Agenda 21" (capítulos $23^{\circ}$ a $32^{\circ}$ ), la "Declaración de Río sobre el Medio Ambiente" y el "Desarrollo de 1992" (principio $10^{\circ}$ ) y la "Declaración de Johannesburgo sobre Desarrollo Sostenible" de 2002 (punto $26^{\circ}$ ), entre otras. Recientemente, la participación también ha sido objeto de reconocimiento en instrumentos bilaterales, como el Acuerdo de cooperación en materia ambiental entre Chile y EE. UU. que complementa el tratado de libre comercio entre ambos países ${ }^{7}$ y el Acuerdo de Cooperación Ambiental entre Chile y Canadá.

En nuestro país, la dictación en 1994 de la Ley No 19.300, sobre: Bases generales del medio ambiente (= LBGMA.) viene a institucionalizar la participación de la ciudadanía en este ámbito. En tal sentido, ya el "Mensaje" del Ejecutivo con que envió el proyecto de la LBGMA. establecía que: "para lograr, una adecuada protección del medio ambiente se requiere de la concurrencia de todos los afectados en la problemática. Por ello, el principio de la participación ciudadana se encuentra presente en todo el desarrollo del proyecto". Concretizando dicho principio, el artículo 4 de la Ley establece el deber del Estado de facilitar la participación ciudadana destinada a la protección del medio ambiente. No obstante ello, desde la dictación de la LBGMA. y reconociendo los avances que este cuerpo normativo introduce en el ordenamiento chileno -quizás el más avanzado de la época-, no se han escatimado las críticas respecto a la restringida participación que institucionaliza esta ley de bases. Incluso algunos autores, no con poca razón, han sostenido que la LBGMA. relega la participación de la comunidad en materia ambiental a

información sobre el medio ambiente, la participación del público en la toma de decisiones y el acceso a la justicia en materia medioambiental de conformidad con las disposiciones del presente Convenio". El Convenio regula la información ambiental, la participación ciudadana en las decisiones ambientales, en políticas, planes y programas, en la elaboración de normas ambientales, y contiene disposiciones sobre el acceso a la justicia ambiental. Chile no es parte de esta Convención Internacional, que se encuentra abierta a la adhesión de países que no son miembros de la Unión Europea.

${ }^{7}$ Cuyo artículo 4 señala: "La Comisión (refiriéndose a la Comisión Conjunta para la Cooperación Ambiental) promoverá el desarrollo de oportunidades para la participación de la sociedad civil en los proyectos de cooperación" y "Cada Parte deberá solicitar, y tomar en consideración cuando sea pertinente, las opiniones de la sociedad civil con respecto a los planes de trabajo y deberá revisar y responder a tales comentarios, de acuerdo con sus propios procedimientos internos".

${ }^{8}$ Cuyo artículo 1 letra h) establece como uno de sus objetivos: "promover la transparencia y la participación de la sociedad en la elaboración de leyes, reglamentos y politicas ambientales".

${ }^{9}$ Mensaje del Ejecutivo № 387-324 del Proyecto de ley sobre bases generales del medio ambiente. 
una mera formalidad ${ }^{10}$. Con todo, la disposición programática que contiene la LBGMA. en su artículo 4 es reproducida por diversos instrumentos normativos, de política y de gestión ambiental, como la Estrategia nacional de biodiversidad, aprobada por el Consejo Directivo de la CONAMA el 2003, que reconoce como uno de sus fundamentos la participación de los diversos sectores sociales en la definición e implementación de las estrategias de conservación de la biodiversidad. En el mismo sentido se pronuncian la Estrategia nacional para la conservación y uso racional de los humedales en Chile, la Politica nacional de áreas protegidas, la Política nacional para la protección de especies amenazadas, la Politica de gestión integral de residuos sólidos, la Política nacional de seguridad química y la Politica ambiental para el desarrollo sustentable.

En este marco, el presente trabajo pretende analizar la concreción del principio participativo en el procedimiento de evaluación de impacto ambiental, en particular, a partir de las modificaciones que introduce en nuestro ordenamiento la Ley $\mathrm{N}^{\circ} 20.417$. El análisis será integrado con las disposiciones generales sobre el procedimiento administrativo, cuya aplicación a la materia permite distinguir dos estatutos de intervención de la ciudadanía: las garantías de participación establecidas por la LBGMA. y las facultades reconocidas a los interesados por la Ley de bases de procedimiento administrativo. Finalmente, se presentan las críticas a la participación en este sector, para lo cual se distingue entre las deficiencias que fueron subsanadas por la reforma legislativa y aquellas que no han sido objeto de modificaciones y que por tanto persisten como debilidades del sistema.

\section{FUNCIÓN DE LOS MECANISMOS PARTICIPATIVOS EN El Sistema de EVAluaCión De impaCto AMBIENTAL}

A la participación ciudadana en la gestión pública se atribuyen diversos efectos positivos que la hacen deseable en todo sistema político; entre ellos, la mejora en la eficacia de las políticas públicas, la educación política, el refuerzo a la solidaridad colectiva y sentido del bien común, el fomento a la asociación, el control social de los agentes de gobierno, la reducción de la carga del aparato público, la contribución al cumplimiento voluntario del ordenamiento jurídico y la legitimación de las decisiones públicas.

En el procedimiento de evaluación de los impactos ambientales de los proyectos o actividades, a la participación podemos asignar dos funciones adicionales de suma trascendencia: servir como mecanismo de prevención y

${ }^{10}$ Fernández, Pedro, Manual de Derecho ambiental chileno (Santiago, Editorial Jurídica de Chile 2004), p. 168. 
resolución de conflictos y como una forma de cooperación de los particulares con la Administración ambiental.

Respecto de lo primero, la participación anterior a la adopción de la decisión sobre el proyecto permite la conciliación y ponderación de intereses en ocasiones divergentes, fomenta la publicidad y, por ende, facilita el entendimiento entre los interesados, pues buena parte de los conflictos ambientales pasan por problemas de información. Lo anterior, como apunta Leme, en la medida que se trate de una participación oportuna y efectiva ${ }^{11}$ y no una mera formalidad que muchas veces termina frustrando las expectativas de los participantes y deslegitimando el Sistema. Para este objeto, según Eduardo Astorga, la Administración debiese tener la posibilidad de reservarse un cierto margen de maniobra a efectos de negociar con las partes en disputa e incluso establecer ciertas condiciones para la realización del proyecto ${ }^{12}$. El proceso participativo bien desarrollado (es decir, con adecuada información y con mecanismos y espacios claros y suficientes) disminuye la conflictividad social. Así, aumenta el nivel de transparencia del proceso, lo que permite un conocimiento más acabado del proyecto o actividad y reduce el manto de dudas sobre su legitimidad y sobre sus efectos, permitiendo a la vez un diálogo entre las partes. De ahí que resulte esencial el rol de la autoridad como facilitadora del proceso de entendimiento entre la comunidad y el proponente. En este sentido, como tiene lugar en el Derecho comparado, la participación puede ser combinada con un proceso formal de mediación a cargo de un tercero que facilite el entendimiento de las partes ${ }^{13}$.

Desde esta perspectiva, la participación permite reducir las probabilidades de judicialización de los conflictos, pues propicia su solución en una fase anterior. Además, permite reforzar la confianza al interior de la comunidad afectada y contribuye a la concientización de la ciudadanía sobre las cuestiones ambientales. Como es natural, las posibilidades de alcanzar acuerdos mediante la participación tienen un límite, luego del cual la decisión recaerá en la Administración, la que por cierto deberá considerar los argumentos de todos los intervinientes que normalmente serán el solicitante (titular del

${ }^{11}$ Leme, Paulo, Direito ambiental brasileiro (Sao Paulo, Malheiros 2010), p. 185.

${ }^{12}$ Astorga, Eduardo, Sistema de evaluación de impacto ambiental. Régimen jurídico en especial aplicado a la actividad minera (Santiago, Editorial Jurídica ConoSur 2000), p. 84.

${ }^{13}$ En el Derecho administrativo norteamericano se faculta a la Administración para determinar libremente la forma alternativa de resolución de conflictos ("alternative dispute resolution" o "adr."), pudiendo someterlo a la intervención de un conciliador, facilitador o mediador. Desde 1980 su utilización se ha incrementado producto del alto costo y del tiempo de los litigios tradicionales. FunK, William - SEAMON, Richard, Administrative Law (New York, Aspen 2006), pp. 98-99. 
proyecto o actividad), demás interesados en el procedimiento (por ejemplo, vecinos que se verán perjudicados con el futuro proyecto) y participantes que no tengan la condición de interesados (como el ciudadano habitante de otra ciudad diversa a la del proyecto, pero que le preocupa la protección del entorno).

En cuanto mecanismo de cooperación, la participación de otros actores enriquece el procedimiento de evaluación de los impactos ambientales del proyecto, incorporando los aspectos sociales en la decisión, como asimismo coadyuvando con la evaluación de elementos técnicos que pueden no ser vislumbrados por la Administración evaluadora. En tal sentido, la participación debe ser abordada no como una carga para el titular o la Autoridad ambiental, sino como una forma de enriquecer el procedimiento y equilibrar los distintos intereses en la decisión final.

A pesar de ello, muchas veces las bondades de la participación no son advertidas, especialmente por los proponentes, que en ocasiones la consideran un trámite infértil fuente de conflictos y que retrasa la ansiada aprobación del proyecto ${ }^{14}$. Para cambiar esta visión se precisa de un marco jurídico adecuado, pero sobre todo de una práctica de la Administración, del titular y de la ciudadanía que permita explotar las potencialidades que presenta la intervención de la ciudadanía en este ámbito.

\section{EL PROCEDIMIENTO DE EVALUACIÓN AMBIENTAL EN CUANTO PROCEDIMIENTO ADMINISTRATIVO}

Antes de analizar los ámbitos en que se considera la participación ciudadana en el "seia", conviene hacer una referencia, por breve que sea, a su naturaleza en cuanto procedimiento administrativo y la aplicación subsiguiente de las disposiciones contenidas en la Ley No 19.880: de Bases de procedimientos administrativos (= LBPA.).

Como se sabe, el procedimiento de evaluación de impacto ambiental de los proyectos y actividades se encuentra normado por la LBGMA. y por el Decreto supremo No 95, de 2001, del Ministerio Secretaría General de la Presidencia, que aprueba el Reglamento del sistema de evaluación de impacto ambiental (= RSEIA.). El objeto del procedimiento es la dictación de un acto administrativo terminal denominado "resolución de calificación ambiental"

${ }^{14}$ Como indica Colil, Martín, Análisis de la estructura del sistema de evaluación de impacto ambiental (tesis para optar al grado de Magíster en Gestión y Planificación Ambiental, Universidad de Chile, Santiago, 2003), p. 47, entre las desventajas de la participación en el "seia" se cuenta el atraso y el costo del proceso, el incremento de expectativas entre los participantes y las situaciones políticas inestables que puede generar un proceso de participación inadecuado. 
(= "rca.") que, en cuanto a su naturaleza, constituye una licencia integrada que remueve un obstáculo para permitir al solicitante el desarrollo de una determinada actividad. La "rca." es, en consecuencia, el acto conclusivo del procedimiento iniciado a solicitud del interesado (titular del proyecto o actividad) y en el que intervienen diversos órganos de la Administración del Estado.

En tanto procedimiento administrativo desarrollado por una Administración del Estado y destinado a la producción de un acto administrativo terminal, le son aplicables las disposiciones contenidas en la LBPA. De acuerdo con el artículo 1 de dicho cuerpo legal y según ha resuelto la jurisprudencia administrativa ${ }^{15}$, sus disposiciones le serán aplicables de forma supletoria, esto es, en aquellas materias no reguladas por la LBGMA. e incluso imponiéndose a la regulación reglamentaria ${ }^{16}$. Tal carácter supletorio determina la integración de los preceptos de la LBPA. al procedimiento especial regulado en la LBGMA.

Según ha consignado la doctrina desde antaño, el procedimiento administrativo surge como reacción natural del Estado liberal de Derecho ante el fenómeno de la asunción de potestades autoritarias por la Administración ${ }^{17}$ y busca encuadrar la actividad administrativa en cauces formales destinados, por una parte, a asegurar el respeto de los derechos de los particulares y, por la otra, a obtener una actuación de la Administración eficaz, oportuna y apegada a la legalidad. Así, la forma de la actuación de la Administración es una de las principales garantías para los particulares y un medio que tiende a que las decisiones de ésta sean acertadas y arregladas a Derecho ${ }^{18}$. Por ello, la necesidad de observar ciertas formas se considera como una garantía de que el contenido se ajustará al ordenamiento jurídico ${ }^{19}$. La función de garantía del

${ }^{15}$ Entre otros, los dictámenes de Contraloría General de la República No 20.119 de 2006 y No 33.448 de 2008.

${ }^{16}$ Tal es el criterio de Contraloría General contenido en dictamen No 39.348, de 30 de agosto de 2007, y en dictamen No 42.639, de 21 de septiembre de 2009; este último que establece: "tratándose de procedimientos contemplados en disposiciones reglamentarias [...], la ley 19880 rige en plenitud, incluso produciendo la derogación de aquellos preceptos de dicho texto reglamentario que sean incompatibles con las disposiciones de este cuerpo legal, en virtud de la aplicación del principio de jerarquia normativa".

${ }^{17}$ Santamaría Pastor, Alfonso, Principios de Derecho administrativo (Madrid, Centro de Estudios Ramón Areces 2002), II, p. 55.

${ }^{18}$ BERMÚDEZ, Jorge, Función y tipología del procedimiento administrativo, en VV. AA., Acto y procedimiento administrativo. Actas de las Segundas Jornadas de Derecho Administrativo (Valparaíso, Ediciones Universitarias de Valparaíso 2005), p. 25.

${ }^{19}$ Royo Villanova, Segismundo, El procedimiento administrativo como garantía jurídica, en Revista de Estudios Políticos, 48 (Madrid, Centro de Estudios Políticos y Constitucionales, 1949), p. 64. Como apunta Garrido Falla, Fernando, Tratado de 
procedimiento administrativo alcanza no sólo a los particulares que inician el procedimiento por medio de una solicitud, sino que comprende a aquellos que, no obstante no haber tenido parte en la iniciación, pueden verse de algún modo afectados con el resultado del procedimiento, es decir, con la resolución final. Esto explica que un conjunto de reglas que estructuran el procedimiento estén dirigidas a materializar la función garantista que cumplen las formas administrativas, tanto respecto del particular solicitante como en relación a terceros cuyos derechos o intereses puedan resultar comprometidos a causa de la decisión de la Administración.

Por ello, de especial relevancia resulta la extensión del concepto de interesados que efectúa el ordenamiento administrativo. En el caso de nuestra LBPA., su artículo 21 reconoce una noción amplia, comprensiva no sólo de los particulares que promueven el procedimiento con una solicitud, sino también de aquellos que pueden resultar afectados en sus derechos o intereses con la decisión final, sea que comparezcan o no en el procedimiento ${ }^{20}$. Tal es el caso, v. gr., de las comunidades vecinas del proyecto que se somete al "seia".

Esta concepción amplia de interesados permite a estos particulares que no son 'parte' originariamente en el procedimiento, hacer valer sus derechos o intereses especialmente a través de los derechos que les concede la LBPA. ${ }^{21}$. Dentro de estas formas garantísticas especial importancia cobran los principios de publicidad y contradictoriedad del procedimiento. El primero de ellos, reconocido en los artículos 16 y 17 letras a) y d) LBPA., permitirá que los particulares puedan imponerse del contenido del mismo, lo que dará sustento al principio de contradictoriedad, recogido principalmente en los artículos 10 y 17 letra f) LBPA. Este principio, inspirador de

Derecho administrativo (4a edición, Institutos de Estudios Políticos, Madrid, 1966), I, p. 501: "El procedimiento administrativo aparece así como un conjunto de formalidades arbitradas, las más de las veces, en garantía del particular. Lo cual no debe hacernos olvidar, sin embargo, la segunda de las finalidades perseguidas con este mismo procedimiento: lograr el mayor acierto y eficacia en las resoluciones administrativas".

${ }^{20}$ Dicho precepto considera interesados en el procedimiento administrativo a: $i$ ) Quienes lo promuevan como titulares de derechos o intereses individuales o colectivos; ii) Los que, sin haber iniciado el procedimiento, tengan derechos que puedan resultar afectados por la decisión que en el mismo se adopte; y iii) Aquéllos cuyos intereses, individuales o colectivos, puedan resultar afectados por la resolución y se apersonen en el procedimiento en tanto no haya recaído resolución definitiva.

${ }^{21}$ Así, el concepto de interesado no calza con el concepto de parte. Tendrán esta condición únicamente aquellos interesados que se han apersonado al procedimiento, en cambio, el concepto de interesados es más amplio pues engloba también a quienes no han intervenido en el procedimiento administrativo, pero que puedan verse afectados en sus derechos por lo que en éste se resuelva. 
todo procedimiento administrativo y en particular del procedimiento en que la Administración ejerce sus potestades sancionadoras, se refiere a la no afectación de derechos o intereses de los particulares sin que éstos tengan la posibilidad de ser oídos y que se ponderen adecuadamente las alegaciones y defensas expuestas ${ }^{22}$. Ello se traduce principalmente en el derecho a acceder al expediente y el derecho a la audiencia, que consiste en la facultad de los interesados de exponer sus argumentos y alegaciones con carácter previo a la adopción de una resolución definitiva por parte de la autoridad administrativa $^{23}$, aportar antecedentes probatorios, alegar defectos de tramitación y ser notificados de la resolución final ${ }^{24}$. Reconociendo tal principio, el artículo 17 LBPA. consagra entre los derechos de las personas en sus relaciones con la Administración: "Formular alegaciones y aportar documentos en cualquier fase del procedimiento anterior al trámite de audiencia, que deberán ser tenidos en cuenta por el órgano competente al redactar la propuesta de resolución". El precepto citado reconoce no sólo la facultad de los particulares de presentar alegaciones y defensas en el procedimiento, sino que establece el deber de la Administración de considerar tales alegaciones y documentos en la resolu-

\footnotetext{
${ }^{22}$ Sobre el particular, refiriéndose al proyecto de Ley de bases de procedimientos administrativos, la Contraloría en dictamen No 2.196, de 28 de enero de 1996, señaló: "los principios establecidos para garantizar el debido procedimiento y los derechos de los administrados, están constituidos por el de: a) contradictoriedad, que garantiza a los particulares hacer valer sus derechos e intereses legitimos ante la autoridad administrativa, al momento en que esta vaya a resolver asuntos que les afecten, involucrando los derechos de audiencia, prueba, defensa y acceso al expediente, considerados en el proyecto".

${ }^{23}$ Cierco, César, La nueva regulación del derecho de audiencia en los procedimientos administrativos comunitarios vinculados a la protección de la competencia, en Revista de Administración Pública, 155 (Madrid, Centro de Estudios Políticos y Constitucionales 2001), pp. 253-254. Como señala Entrena Cuesta, Rafael, Curso de Derecho administrativo, Ed. (Madrid, Tecnos 1995), I,1, p. 259, la audiencia se traduce en "el derecho de los interesados en un procedimiento a examinar el expediente y formular alegaciones y la consiguiente obligación que sobre la Administración pesa de proporcionarles esta oportunidad constituyen, acaso, en el orden procedimental la mejor garantía de la seguridad jurídica de aquellos".

${ }^{24} \mathrm{El}$ precepto establece: "Principio de contradictoriedad. Los interesados podrán, en cualquier momento del procedimiento, aducir alegaciones y aportar documentos $u$ otros elementos de juicio. / Los interesados podrán, en todo momento, alegar defectos de tramitación, especialmente los que supongan paralización, infracción de los plazos señalados o la omisión de trámites que pueden ser subsanados antes de la resolución definitiva del asunto. Dichas alegaciones podrán dar lugar, si hubiere razones para ello, a la exigencia de la correspondiente responsabilidad disciplinaria. / Los interesados podrán, en todo caso, actuar asistidos de asesor cuando lo consideren conveniente en defensa de sus intereses. / En cualquier caso, el órgano instructor adoptará las medidas necesarias para lograr el pleno respeto a los principios de contradicción y de igualdad de los interesados en el procedimiento".
} 
ción final ${ }^{25}$. Esta última parte es de suma importancia ya que se traduce, en definitiva, en que las alegaciones de los particulares interesados, aun cuando no hayan tomado parte en la iniciación del procedimiento, deben ser parte del fundamento del acto terminal, en nuestro caso, en la "rca.". La falta de consideración en la resolución final constituye un vicio en el motivo y contenido del acto y una infracción a los principios conclusivo, de imparcialidad, objetividad y contradictoriedad.

La oportunidad para ejercer el derecho de audiencia, como se señaló (véase la nota 25), debe extenderse hasta el momento culminante del procedimiento, pues carece de sentido restringir la posibilidad de aducir alegaciones y defensas a una etapa inicial. En definitiva, el principio de contradictoriedad permite que particulares que no han iniciado el procedimiento intervengan en éste y ejerzan la defensa de sus derechos o intereses mediante el derecho a audiencia que comprende no sólo la defensa en el curso del procedimiento, sino la obligación de la Administración de considerar las alegaciones y notificarlos de la resolución final, así como la facultad de impugnar el acto terminal (tanto por vicios del acto en sí mismo como por defectos del procedimiento) en sede administrativa y judicial.

Finalmente, resultan plenamente aplicables al procedimiento de evaluación de impacto ambiental el principio de imparcialidad, consagrado en el artículo 11 LBPA, que exige a la Administración actuar con objetividad, es decir, no perjudicar ni favorecer a personas determinadas sino observar siempre el interés público ${ }^{26}$; el principio de impugnabilidad, reconocido en los artículos 6,7,19 No 3 (en lo referente al acceso a la justicia como integrante del debido proceso) y 38 inciso 2 de la Carta Fundamental, en los artículos 2, 3 inciso 2 y 10 Ley No 18.575: Orgánica constitucional sobre

${ }^{25} \mathrm{El}$ error del precepto, sin embargo, es que limita esta garantía a la fase "anterior al trámite de audiencia". Esta equivocación del legislador es producto de una irrazonada copia de la Ley de régimen jurídico de las administraciones públicas y procedimiento administrativo común española, de 1992. La LBPA. no establece un trámite de audiencia como comparendo específico en el íter procedimental, sino sólo respecto del procedimiento especial de invalidación (artículo 53) y cuando se resuelven cuestionas conexas en la resolución final (artículo 41). La solución para superar este error legislativo puede ser considerar que esta garantía de aducir alegaciones y documentos puede tener lugar hasta antes de la redacción de la propuesta de resolución.

${ }^{26}$ Zanella, María Sylvia, Direito administrativo (23a edición, Sao Paulo, Atlas, 2010), p. 67. Sobre el particular, refiriéndose al proyecto de Ley de bases de procedimientos administrativos, la Contraloría, en dictamen № 2.196, de 28 de enero de 1996, señaló que el principio de imparcialidad: "asegura la plena realización o consecución del bien común, al margen de otros intereses o consideraciones particulares no objetivas, como el favorecer a parientes o actuar en beneficio politico partidista, o perseguir a personas por razones ajenas al interés publico". 
bases generales de la Administración del Estado (= LBGAE.) y en los artículos 4, 15, 41 inciso $4^{\circ}$ y 54 LBPA., que permite a los particulares interesados ejercer los medios de impugnación en sede administrativa y judicial contra los actos administrativos terminales ${ }^{27}$; y el deber de motivación, establecido en los artículos 11 inciso 2 y 4 LBPA., que impone a la Administración el deber de indicar los fundamentos de hecho y de derecho de las decisiones y que constituye una formalidad necesaria para permitir el control de los actos administrativos ${ }^{28}$.

En suma, a partir de la aplicación de las disposiciones de la LBPA. al procedimiento del "seia", es posible distinguir dos estatutos que permiten la participación de la ciudadanía: $i$ ) el estatuto conformado por las disposiciones de la LBGMA. que a continuación se analizan y que permiten una participación extensa de la ciudadanía; y ii) el estatuto conformado por las disposiciones de la LBPA. que permiten a aquellos que tengan la condición de interesados formular sus observaciones al procedimiento y, en general, ejercer el derecho de audiencia ${ }^{29}$. Este último conjunto de disposiciones, a

${ }^{27}$ Lo cual no quiere decir que los defectos de tramitación sean ininpugnables, pues, salvo cuando produzcan indefensión, éstos pueden impugnarse en el acto terminal. En otros términos, la impugnación de los vicios de los actos trámites por razones de economía procedimental se reserva para la impugnación del acto terminal.

${ }^{28}$ En tal sentido, el dictamen de la Contraloría No 44.144, de 21 de septiembre de 2005, resolvió que: "los actos pertinentes, exigen un especial y cuidadoso cumplimiento de la necesidad jurídica en que se encuentra la administración de motivar sus actos, con el objeto de asegurar que ellos no se desvien del fin considerado por la normativa que confiere las atribuciones, o sea, que ellos cuenten con un fundamento racional y se encuentren plenamente ajustados a la normativa constitucional y legal vigente. Esta obligación se fundamenta en el principio de juridicidad que, en un concepto amplio y moderno, conlleva la exigencia que los actos administrativos tengan una motivación y un fundamento racional y no obedezcan a un mero capricho de la autoridad pues, en tal caso, resultarian arbitrarios y, por ende, ilegítimos". En análogo sentido se pronuncia el dictamen $N^{\circ} 60170$ de 19 de diciembre de 2008, que establece: "Cabe recordar que la exigencia de fundamentación de los actos administrativos se relaciona con el recto ejercicio de las potestades otorgadas a la Administración activa, toda vez que permite cautelar que éstas se ejerzan de acuerdo a los principios de juridicidad -el que lleva implícito el de racionalidad, evitando todo abuso o exceso, de acuerdo con los artículos $6^{\circ}$ y $7^{\circ}$ de la Constitución Politica de la República, en relación con el artículo $2^{\circ}$ de la ley $N^{\circ} 18.575$, Orgánica Constitucional de Bases Generales de la Administración del Estado-, y de igualdad y no discriminación arbitraria -contenido en el artículo 19, $N^{\circ}$ 2, de la Carta Fundamental-, como asimismo, velar porque tales facultades se ejerzan en concordancia con el objetivo considerado por el ordenamiento jurídico al conferirlas" y "En este contexto, considerando que los actos de la Administración deben ser fundados, procede que la Municipalidad de Vitacura, al ejercer sus atribuciones, tenga en cuenta dichos fundamentos [refiriéndose a la solicitud de plebiscito] al establecer las materias y sectores objeto del plebiscito".

${ }^{29}$ Además, habría un tercer estatuto conformado por las disposiciones autoejecuta- 
pesar del carácter supletorio de la LBPA., resulta plenamente aplicable en tanto la LBGMA. no contiene una regulación diversa sobre los interesados y los derechos que a éstos corresponden, puesto que sólo contiene regulaciones relativas a la participación ciudadana cuyo objeto y titularidad son de naturaleza distinta.

\section{LAS MODALIDADES DE PARTICIPACIÓN EN EL SISTEMA DE EVALUACIÓN DE IMPACTO AMBIENTAL ANTES DE LA REFORMA INTRODUCIDA POR LA LEY No 20.417}

El artículo 10 LBGMA. contiene un listado de proyectos que sólo pueden ejecutarse o modificarse previa evaluación de su impacto ambiental. La forma de someterse al sistema es a través de "estudio de impacto ambiental" ("eia.") o "declaración de impacto ambiental" ("dia."), según se verifiquen o no los efectos, características o circunstancias establecidas en el artículo 11. La finalidad del procedimiento, que constituye una obligación del Estado contraída en diversos instrumentos internacionales ${ }^{30}$, es hacer aplicación del principio preventivo que exige adoptar las medidas pertinentes para evitar daños o conflictos ambientales ${ }^{31}$.

De acuerdo a lo dispuesto por el artículo 14 de LBGMA. antes de la

bles del Convenio No 169 de la OIT: sobre Pueblos originarios, a pesar que la interpretación de nuestros tribunales en materia de participación de las comunidades indígenas en materia ambiental -a diferencia de en otros ámbitos como en lo relativo a los derechos de aguas- ha sido muy formalista. En los casos ventilados hasta la fecha la judicatura ha señalado que no resulta procedente la realización de consulta adicional si en el procedimiento del SEIA se consideró la fase de participación ciudadana. En tal sentido la Corte Suprema, en la reciente sentencia rol No 4.078-2010, de fecha 14 de octubre de 2010, considerando séptimo, establece: "Que conforme a estos lineamientos, forzoso es concluir que el deber general de consulta a los pueblos indigenas en lo concerniente a los procedimientos de evaluación de impacto ambiental estatuido en la Ley $N^{\circ} 19.300$ y su Reglamento ya se encuentra incorporado a dicha legislación ambiental a través del procedimiento de participación ciudadana que los artículos 26 a 31 de la citada ley establecen". La misma doctrina recoge posteriormente la sentencia de la Corte de Apelaciones de Antofagasta, rol No 782-2010, de 21 de diciembre de 2010.

${ }^{30}$ La participación en la evaluación ambiental de proyectos es una exigencia internacional contenida en el artículo 14,1 letra a) del Convenio sobre la diversidad biológica, precepto que dispone que cada Estado parte: "Establecerá procedimientos apropiados por los que se exija la evaluación del impacto ambiental de sus proyectos propuestos que puedan tener efectos adversos importantes para la diversidad biológica con miras a evitar o reducir al minimo esos efectos y, cuando proceda, permitirá la participación del público en esos procedimientos".

${ }^{31}$ El mensaje del proyecto de la LBGMA. (cit. n. 9) establecía: "mediante este principio, se pretende evitar que se produzcan los problemas ambientales. No es posible continuar 
reforma introducida por la Ley No 20.417 en enero de $2010^{32}$, el procedimiento administrativo para la tramitación de los eias. debía contemplar la participación de organizaciones ciudadanas. Según la regulación original de la LBGMA. y del RSEIA., esta fase de participación se iniciaba con la publicación en el Diario Oficial y en un diario de circulación local o nacional, según el ámbito del proyecto, de un extracto del "eia." presentado, que debía realizar el titular del proyecto o actividad. De conformidad con lo dispuesto por el artículo 28 LBGMA. antes de la comentada reforma, las "organizaciones ciudadanas con personalidad juridica, por intermedio de sus representantes, y las personas naturales directamente afectadas" tenían derecho a imponerse del contenido del Estudio y de los documentos acompañados, salvo las excepciones que consultaba la misma disposición ${ }^{33}$. A partir de la publicación del extracto, las personas y entidades antes señaladas podían formular observaciones al Estudio de Impacto Ambiental dentro del plazo de sesenta días contados desde la última publicación, ante la COREMA o la CONAMA, según correspondiera. La referida entidad Administrativa, como prescribía el artículo 29, debía ponderar en los fundamentos de su resolución las observaciones, es decir, el legislador imponía expresamente a la Administración el deber de pronunciarse sobre las observaciones de la ciudadanía, lo que representaba una manifestación de los principios de imparcialidad, contradictoriedad y publicidad de la actuación administrativa comentados supra.

Si las organizaciones o personas naturales participantes estimaban que sus observaciones no fueron debidamente ponderadas en los fundamentos de la "rca.", podían deducir un recurso administrativo especial ante la autoridad

con la gestión ambiental que ha primado en nuestro pais, en la cual se intentaba superar los problemas ambientales una vez producidos".

${ }^{32}$ La Ley No 20.417, publicada en el $D O$. de 26 de enero de 2010, modifica la LBGMA. para sustituir la institucionalidad ambiental, creando al efecto el Ministerio del Medio Ambiente, el Servicio de Evaluación Ambiental y la Superintendencia del Medio Ambiente. Además, reforma aspectos sustantivos de los instrumentos de gestión ambiental para adaptarlos a los requerimientos de la Organización para la Cooperación y el Desarrollo Económico y modifica diversos cuerpos legales.

${ }^{33}$ Antecedentes técnicos, financieros y otros, a objeto de asegurar la confidencialidad comercial e industrial, o proteger las invenciones o procedimientos patentables del proyecto o actividad. Asimismo, según el artículo 52 RSEIA., las organizaciones ciudadanas con personalidad jurídica y las personas naturales podían solicitar copia del "eia." en los lugares que indica la publicación en el diario. En la práctica, en las oficinas de CONAMA regional o nacional y especialmente en sus centros de documentación, se colocaban las carpetas para su revisión por parte de la ciudadanía. Además, algunas direcciones regionales entregaban al Consejo Consultivo Regional mes a mes el listado de proyectos que ingresaban a tramitación y de los proyectos aprobados por la COREMA. 
superior dentro de los quince días siguientes a su notificación. Este recurso ad hoc no suspendía los efectos de la resolución recurrida y su objeto, como apuntaba el profesor Jorge Bermúdez, no era la anulación del acto administrativo sino su modificación en el sentido de la debida consideración de las observaciones desatendidas ${ }^{34}$ (los efectos del recurso serán abordados en $\mathrm{V}, 3$. Sin embargo, si la Administración desestimaba el recurso, la ciudadanía carecía de legitimación activa para ejercer la reclamación ante el juez civil contenida en el original artículo $60^{35}$ (pues como se verá, esta acción era sólo para el titular del proyecto cuando éste era rechazado o se le imponían condiciones o exigencias al "eia." ${ }^{36}$ ).

El artículo 29 inciso $2^{\circ}$ LBGMA. ordenaba la notificación de la "rca." a las personas naturales o jurídicas que hubieren formulado observaciones. Asimismo, se disponía la notificación a éstos de la resolución que resolvía el recurso administrativo especial recién comentado (cuando las observaciones no fueron ponderadas según el artículo 46 inciso final RSEIA), así como aquella que decidía sobre el recurso de reclamación deducido por el titular del proyecto cuando la "rca." le era denegada o imponía condiciones o exigencias al "eia." (esto último por disposición del artículo 44 inciso 4 RSEIA., a pesar que el artículo 20 inciso final LBGMA. no lo decía).

Además de esta forma de participación, según los artículos 26 LBGMA. y 49 RSEIA., correspondía a la CONAMA o COREMA, según el caso, establecer los mecanismos que aseguraran la participación informada de la comunidad organizada en el proceso de evaluación de eias. De acuerdo con lo dispuesto por el inciso 2 del artículo 49 del RSEIA., dichos mecanismos serían establecidos en forma específica en cada caso, dependiendo de las características propias del proyecto o actividad, y se podía solicitar la participación

${ }^{34}$ Bermúdez, Jorge, Fundamentos de Derecho ambiental (Valparaíso, Ediciones Universitarias de Valparaíso 2007), p. 216.

${ }^{35}$ Durante la tramitación del proyecto en la Cámara de Diputados se propuso una indicación para que aquellos cuyas observaciones no fueron acogidas pudieran recurrir ante los tribunales de justicia, mas ella fue rechazada por temor a que se pudiese producir una utilización abusiva de la vía judicial. Dinamarca, Jaime, Evaluación de impacto ambiental. Análisis del reglamento actualizado (Santiago, LexisNexis 2003), p. 149. En mi concepto, se trata de un temor infundado que perjudica en vez de colaborar en el equilibrio de intereses en el procedimiento de evaluación de impacto ambiental y es contraria a los principios de contradictoriedad, igualdad y acceso a la justicia. Uno de los efectos de este tipo de decisiones es que se fuerza la utilización del recurso de protección como paliativo ante la inexistencia de vías especiales de impugnación, con las limitaciones que esta acción constitucional presenta en la materia.

${ }^{36}$ En un sentido contrario, KitTsteiner, Enrique, Derecho ambiental (Santiago, Aremi 2004), p. 184 sostenía que el recurso de reclamación judicial sí correspondía a la ciudadanía.. 
de los órganos del Estado con competencia ambiental o con competencia en materia de desarrollo comunitario o social, o de participación ciudadana. Ello permitiría establecer otros mecanismos participativos en el marco de la evaluación del "eia." En la práctica CONAMA y las COREMAs solían organizar talleres de discusión ciudadana, generalmente en colaboración con las unidades ambientales de los municipios. En estos talleres se exponían las líneas generales del proyecto, se daba respuesta a las consultas ciudadanas y se recibía la opinión de la comunidad.

Finalmente, en la práctica se reconocía también una suerte de participación en las días. a través del ejercicio del derecho de petición (artículo $19 \mathrm{~N}^{\circ}$ 14 C.Pol.). Si bien la regulación constitucional de esta garantía no impone a la Administración el deber de contestar, la Contraloría General ha entendido que "la autoridad administrativa esta obligada a contestar por escrito las solicitudes que formulen los particulares en el ejercicio del derecho de petición, sea acogiendo o denegando lo solicitado o bien, cuando carezca de competencia, debe limitarse a declarar ese hecho, siempre que el peticionario proceda en términos respetuosos y convenientes" ${ }^{37}$. Así, era habitual que la autoridad ambiental contestará las observaciones que se formularan a una "dia." en virtud de la garantía en referencia, aunque no existía una ponderación de las mismas ni el deber de considerarlas en los fundamentos de la "rca.", de modo que su efecto era en general nimio.

\section{LAS MODIFICACIONES INTRODUCIDAS POR LA LEY No 20.417}

Como es sabido, la Ley № 20.417, de enero de 2010, modifica no sólo la institucionalidad, sino también introduce reformas sustantivas al ordenamiento ambiental y, en particular, a los instrumentos de gestión. Dentro de las modificaciones que experimenta el "seia", en lo que nos interesa, se modifican todos los artículos del párrafo $3^{\circ}$ relativo a la participación de la comunidad, añadiéndose dos disposiciones nuevas (los artículos 30 bis y 30 ter), y se agrega además el párrafo $3^{\circ}$ bis: Del Acceso a la información ambiental.

El punto de partida para examinar las reformas viene dado por la definición de participación ciudadana que efectúa el inciso final del artículo 30 bis, según el cual ésta comprende los derechos a acceder y conocer el expediente físico o electrónico de la evaluación (derecho de información ambiental), a formular observaciones y a obtener respuesta fundada de ellas, materias todas que a continuación se analizan.

${ }^{37}$ Dictamen No 13.272, de 3 de mayo de 1990. 


\section{Información ambiental.}

La posibilidad de ejercer una participación fundada y, en particular, de impugnar el acto administrativo, supone tener conocimiento de la iniciación del procedimiento y acceder al acto mismo, a la fundamentación de la decisión y al expediente administrativo ${ }^{38}$. Asimismo, Somanathan ha demostrado una correlación entre el nivel de información ambiental y la calidad del entorno, en tanto un aumento en el nivel de la información disponible permite a la ciudadanía tomar conciencia de los problemas ambientales, lo que motiva el desarrollo de acciones destinadas a mejorar tal estado de $\operatorname{cosas}^{39}$. La información se presenta, en definitiva, como el sustrato de la participación ciudadana, aunque no constituye en sí misma una modalidad participativa, pues los ciudadanos no toman parte sino que son receptores de la comunicación.

Como se adelantó, el nuevo artículo 27 amplía el alcance de esta garantía a "cualquier persona, natural o jurídica", superando la formulación anterior que restringía el acceso a las organizaciones ciudadanas con personalidad jurídica-que lo ejercían por intermedio de sus representantes-y las personas naturales directamente afectadas. En consecuencia, el derecho de acceso a la información en la materia no se circunscribe a las organizaciones de carácter ciudadano con personalidad jurídica ni tampoco a aquellos que tengan la condición de directamente afectados. De este modo, a partir de la reformulación del precepto en comento, por ejemplo, una sociedad anónima es titular del derecho de acceso a la información ambiental, así como también lo es una persona natural que puede no ser afectada por el proyecto $y$, por ende, no tener la condición de interesado en el procedimiento administrativo. La extensión en la titularidad del derecho a acceder a la información ambiental es concordante con el estatuto general introducido por la Ley No 20.285 . sobre: Acceso a la Información Pública (= LAIP.), cuyo artículo 10 lo consagra respecto de "toda persona", tenga o no interés en el procedimiento y sin que le sea exigible precisar en la solicitud de acceso las razones de la misma ${ }^{40}$.

\footnotetext{
${ }^{38}$ La materia fue abordada en: Bermúdez, Jorge - Mirosevic, Camilo, El acceso a la información pública como base para el control social y la protección del patrimonio público, en Revista de Derecho de la Pontificia Universidad Católica de Valparaíso, 31 (Valparaíso, 2008), p. 451.

${ }^{39}$ En tal sentido, Somanathan, E., Effects of Information on Environmental 2uality in Developing Countries, en Review of Environmental Economics and Policy, 4, No 2 (Oxford, verano de 2010) 2, p. 275, expresa: "If people are not aware of environmental risks, they will be less willing to pay to reduce them. Thus, providing people with information about environmental hazards may increase welfare by raising environmental quality to a more appropriate level".

${ }^{40} \mathrm{El}$ precepto establece: "Toda persona tiene derecho a solicitar y recibir información de cualquier órgano de la Administración del Estado, en la forma y condiciones que esta-
} 
Así, el artículo 27 LBGMA. consagra el derecho de acceso al expediente a cualquier persona, natural o jurídica, para imponerse del contenido del proyecto y del tenor de los documentos acompañados por el titular, reconociendo excepciones relativas a la reserva de ciertos antecedentes sensibles en términos similares a la regla antes comentada (vide n. 33$)^{41}$. En cuanto al objeto de este derecho, por una parte el artículo 31 bis reconduce al régimen general de acceso a la información pública contenida en la LAIP., define lo que se entiende por información ambiental reconociendo sus diversos soportes (escrita, visual, sonora, electrónica o registrada en cualquier otra forma $)^{42}$ y se remite finamente al amparo de información contenido en la LAIP. cuando este derecho de acceso sea lesionado.

Por otra parte, la reforma introduce diversas medidas de publicidad que innovan respecto del régimen general y que son adicionales a las publicaciones antes comentadas, entre las cuales conviene destacar la obligación de los proponentes de anunciar mediante mensajes en medios de radiodifusión local la presentación de una "dia." o "eia.”, el lugar donde se encuentran disponibles sus antecedentes y el plazo para realizar observaciones. Cuando esta medida de publicidad resulte excesivamente onerosa o no sea posible su realización por razones técnicas, el director regional o el director ejecutivo del Servicio de Evaluación Ambiental (SEA) puede autorizar su reemplazo por otro medio de similar alcance, como podrían ser, por ejemplo, la publicación de avisos de publicidad en ciertos lugares concurridos, la difusión en diarios locales, sean en formato papel o electrónico ${ }^{43}$, entre otros. Además, respecto de la publicación del extracto dando a conocer la presentación de un "eia." de acuerdo a lo dispuesto por el artículo 28 en su inciso final, en caso que el Estudio hubiese sido objeto de aclaraciones, rectificaciones o ampliaciones que afecten sustantivamente los impactos ambientales del proyecto, el proponente debe

blece esta ley. I El acceso a la información comprende el derecho de acceder a las informaciones contenidas en actos, resoluciones, actas, expedientes, contratos y acuerdos, asi como a toda información elaborada con presupuesto público, cualquiera sea el formato o soporte en que se contenga, salvo las excepciones legales".

${ }^{41}$ La regla de excepción debe compatibilizarse con lo dispuesto por el artículo 8 C.Pol. y con la LAIP.

${ }^{42}$ Sin perjuicio de la definición de información ambiental que contiene este cuerpo legal, por aplicación del artículo 11 letra c) LAIP, cualquier otra información distinta que obre en poder de la Administración se presume pública.

${ }^{43}$ Respecto de la posibilidad de efectuar las publicaciones en medios electrónicos, la Contraloría, en dictamen No 60.513, de 2004, señaló: "Si la ley exige efectuar una publicación en un diario, ésta debe realizarse en las condiciones que prescriba la normativa correspondiente y en tales casos y salvo que los términos de la exigencia legal obsten a esta posibilidad-como sucede con los actos a que se refiere el articulo 48 de la ley $N^{\circ} 19880$-no se aprecian inconvenientes para que dicha publicación se efectúe en un diario electrónico". 
publicar un nuevo extracto cumpliendo con las mismas condiciones de la publicación original (en el Diario Oficial y en un periódico de la capital regional o de circulación nacional, dependiendo del ámbito territorial del proyecto $\mathrm{y}$, aunque la Ley no lo indica, además por medios radiales o en los medios alternativos si fueron empleados originalmente). El objeto de esta medida es dar a conocer a la comunidad la existencia de modificaciones sustanciales al "eia.", como a la vez informarles que, según el artículo 29, a partir de la referida publicación se abre un nuevo periodo de participación ciudadana para la formulación de observaciones, respecto, claro está, de las modificaciones ${ }^{44}$. De forma similar, el artículo 30 establece que las Comisiones de Evaluación o el director ejecutivo del SEA deben publicar mensualmente un listado de las "dias." presentadas en el mes anterior. Según el inciso final de dicho precepto, en caso de presentarse modificaciones sustanciales a la "dia." el proponente debe efectuar una publicación dando a conocer el contenido de las mismas. Como puede advertirse, y al igual que en el caso del "eia.", la medida busca informar a la ciudadanía de la modificación sustantiva a la "dia." y a la vez comunicar la apertura del nuevo periodo de formulación de observaciones cuando originalmente lo hubo, o, en caso contrario, permitir a la ciudadanía solicitar la apertura de un proceso de participación ciudadana respecto de las modificaciones en los términos del inciso 1 del artículo 30 bis, es decir, cuando producto de ellas el proyecto sea meritorio de considerar una etapa de participación ciudadana ${ }^{45}$.

Respecto del régimen de notificaciones, aunque la Ley nada dice a diferencia del texto anterior, el referido acto terminal debe ser notificado a los ciudadanos u organizaciones que formularon observaciones, y ha de señalar que en su contra procede el recurso de impugnación contenido en el artículo 20 LBGMA. si consideran que sus observaciones no fueron ponderadas,

${ }^{44}$ Debe recordarse que en el extracto se hace un llamado a las organizaciones ciudadanas con personalidad jurídica y a los ciudadanos directamente afectados a presentar sus observaciones debidamente fundadas y por escrito, en el plazo de sesenta días. A partir de la entrada en vigencia de la reforma, estas observaciones pueden también formularse por medios electrónicos.

${ }^{45}$ Aunque la disposición parece colocarse en el supuesto de que el proceso de participación se solicita respecto de la publicación original de la "dia.". Nada impide, sin embargo, que habiéndose efectuado las publicaciones originales relativas a una "dia." y no habiéndose ordenado la apertura de un proceso de participación por no presentarte el supuesto que lo hace procedente, se requiera su realización luego de las publicaciones derivadas de modificaciones sustanciales, naturalmente respecto de tales alteraciones o de las demás partes del proyecto original vinculadas con ellas. De lo contrario bastaría presentar una "dia." incompleta sin demostrar que el proyecto genera cargas ambientales, para luego introducirle modificaciones sustanciales y completar por esa vía el proyecto, para evadir el trámite de participación. 
por exigencia del artículo 41 inciso 4 LBPA. que establece como parte del objeto o contenido del acto la expresión de los recursos que contra el mismo proceden, aunque su omisión no constituye un vicio invalidante del acto. Asimismo, la "rca." deberá notificarse a los interesados, hayan o no formulado observaciones, dado que la falta de participación en el periodo no les impide formular sus alegaciones ni ejercer los derechos que la LBPA. les reconoce. Según el artículo 53 RSEIA., cuando la resolución deba comunicarse a un gran número de personas y ello dificulte considerablemente la práctica de la diligencia, se podrá publicar un aviso en el Diario Oficial y en un periódico de la capital de la región o de circulación nacional, según corresponda. Respecto de los interesados, hayan o no formulado observaciones (por ejemplo, aquel vecino del proyecto que se verá afectado por las emisiones a la atmósfera), en mi concepto, la falta de notificación impedirá la ejecución del acto administrativo, toda vez que según ordena el artículo 51 inciso final LBPA., las resoluciones producen efectos jurídicos desde su notificación o publicación, según sean de contenido individual o general ${ }^{46}$. Ello supone, por una parte, que a los interesados a quienes no se notificó el acto no les corre plazo para la interposición de los recursos administrativos pertinentes en tanto dicha comunicación no se les efectúe, sin perjuicio de la notificación tácita del artículo $47 \mathrm{LBPA}^{4}{ }^{47}$. Por otro lado, el titular no podrá iniciar la ejecución del proyecto por no encontrarse firme el acto administrativo que remueve el obstáculo para el ejercicio de su derecho preexistente ${ }^{48}$. Finalmente, el artículo 25 quáter dispone expresamente que la "rca." debe ser informada a la comunidad.

En suma, la "rca." debe notificarse al proponente, a las personas naturales o jurídicas que formularon observaciones, a los interesados -hayan o no

${ }^{46} \mathrm{El}$ artículo 51 dispone: "Ejecutoriedad. Los actos de la Administración Pública sujetos al Derecho Administrativo causan inmediata ejecutoriedad, salvo en aquellos casos en que una disposición establezca lo contrario o necesiten aprobación o autorización superior. / Los decretos y las resoluciones producirán efectos jurídicos desde su notificación o publicación, según sean de contenido individual o general".

${ }^{47}$ El artículo 47 LBPA. establece: "Notificación tácita. Aun cuando no bubiere sido practicada notificación alguna, o la que existiere fuere viciada, se entenderá el acto debidamente notificado si el interesado a quien afectare, biciere cualquier gestión en el procedimiento, con posterioridad al acto, que suponga necesariamente su conocimiento, sin haber reclamado previamente de su falta o nulidad".

${ }^{48}$ En tal sentido la Contrañoría, en dictamen No 957, de 8 de enero de 2010, concluyó: "En lo que interesa, según lo dispone el artículo 51 de la ley $N^{\circ} 19.880$, los actos administrativos sólo producirán los efectos que les son propios en virtud de la notificación hecha de conformidad a la ley, de manera que aquélla constituye un requisito necesario para la eficacia de esos actos". 
formulado observaciones-, e informada a la comunidad, a los organismos intervinientes en el proceso y a la Superintendencia del Medio Ambiente.

2. Derecho a formular observaciones.

a) Aspectos generales: El segundo peldaño corresponde al derecho a formular observaciones, que, a diferencia de la información ambiental, sí constituye una modalidad de participación de la ciudadanía.

En cuanto a su titularidad, el derecho a formular observaciones experimentó una expansión en comparación con la redacción anterior a la modificación en análisis, toda vez que, mientras en la versión original de la LBGMA. éste se confería a las organizaciones ciudadanas con personalidad jurídica y a las personas naturales directamente afectadas (según el artículo 29 antes de la modificación $)^{49}$, desde enero de 2010 se atribuye a "cualquier persona, natural o jurídica". Por tanto, ahora pueden participar no sólo organizaciones ciudadanas, sino también otras entidades con existencia legal (v. gr. cooperativas, partidos políticos, iglesias, comunidades agrícolas, corporaciones, fundaciones, comunidades indígenas, juntas de vecinos y demás organizaciones funcionales e incluso sociedades), y asimismo, personas naturales aunque no sean afectadas directamente por el proyecto (de modo que una persona que reside en Arica podría formular observaciones respecto de un proyecto que se pretende instalar en Aysen, por ejemplo). Estas modificaciones constituyen un avance en el sentido que reconocen la naturaleza común del entorno y la universalidad del daño (que podría afectar no sólo a quien reside directamente en el área del proyecto, sino al resto de la colectividad e incluso a las generaciones venideras) y puesto que configuran al mecanismo como una forma de participación que sirve no sólo a la defensa de intereses particulares (de los directamente afectados), sino también de intereses difusos y del interés general.

${ }^{49}$ Incluso el proyecto original de LBGMA. enviado al Congreso no consideraba la intervención de las personas naturales en este procedimiento, sino únicamente a las organizaciones ciudadanas con personalidad jurídica. La inclusión de "las personas naturales directamente afectadas" se produjo en la Comisión de Recursos Naturales, Bienes Nacionales y Medio Ambiente de la Cámara de Diputados, y se argumentó que "resultaba arbitrario excluir del conocimiento de estos antecedentes a los afectados, en términos de lesionar las respectivas garantías constitucionales". VÉASE: MORENO, Carlos, cit. (n. 5), pp. 76-77. Esto explicaba la razón de por qué el antiguo artículo 26 LBGMA. antes de la modificación de enero de 2010, que inauguraba el párrafo sobre "Participación de la Comunidad en el Procedimiento de Evaluación de Impacto Ambiental”, encargaba a la CONAMA y COREMAS establecer los mecanismos que aseguren la participación de la "comunidad organizada", sin incluir a las personas naturales afectadas. Igualmente, el artículo 14 en su letra d) disponía que el Reglamento del SEIA debía considerar la participación de las "organizaciones ciudadanas". 
Desde la perspectiva orgánica, el legislador de la Ley No 20.417, en el artículo 81 letra h), encarga al SEA fomentar y facilitar la participación ciudadana en la evaluación de proyectos. Asimismo, el artículo 26 encarga a esa autoridad, así como a las Comisiones de Evaluación, establecer mecanismos que aseguren la participación informada de la "comunidad" (ya no de la "comunidad organizada" como en la versión original), de modo que podrían disponer la realización de otras formas participativas adicionales a las establecidas en la LBGMA., como la distribución de resúmenes del proyecto, colocar afiches en lugares públicos, la realización de reuniones informativas con las juntas de vecinos y demás organizaciones, apertura de buzones de opinión, entrega de los eias. y días. a las organizaciones de la comuna, etcétera. A ello se suma el rol que corresponde a la municipalidad en el proceso (normalmente a través de las Unidades Municipales de Medio Ambiente), quienes pueden facilitar su difusión y realizar actividades en tal dirección, idealmente en coordinación con el SEA.

En cuanto a la forma de presentación de las observaciones, se mantiene la posibilidad de hacerlo por escrito por medios tradicionales, pero se añade la opción de expresarlas por medios electrónicos, según ordena el artículo 14 bis, cuestión de toda lógica atendido que el procedimiento del "seia" se contiene también en este soporte.

b) Participación en la evaluación de los “eia." Esta modalidad de participación se mantiene en términos similares a la formulación original de la Ley. La innovación que debe felicitarse y que viene a subsanar una de las principales deficiencias de la LBGMA. en su versión anterior, es que el artículo 29 inciso $2^{\circ}$ dispone la apertura de una nueva etapa de participación en caso de modificaciones substanciales al "eia." en el curso de su evaluación, como se había adelantado. Esta nueva fase permite una participación completa de la ciudadanía respecto de la totalidad del "eia." objeto del procedimiento de evaluación, considerando que en la evaluación el proponente suele variar los términos originales del proyecto a través de adendas.

c) Participación en la evaluación de las "dias." La modificación más trascendente que introduce la Ley No 20.417 reside en que el artículo 30 bis permite al director regional o ejecutivo del SEA, de acuerdo con los criterios que fijará al efecto el Consejo de Ministros para la Sustentabilidad según el artículo 71 letra e), ordenar la realización de un proceso de participación ciudadana en la evaluación de una "dia." por un plazo de veinte días. El supuesto de la disposición es que el proyecto genere cargas ambientales para las comunidades próximas, lo que tendrá lugar respecto de aquellos proyectos que producen beneficios sociales y que ocasionan externalidades ambientales negativas en localidades próximas en su fase de construcción 
y operación ${ }^{50}$. La apertura del proceso debe ser solicitada por escrito por, a lo menos, dos organizaciones ciudadanas con personalidad jurídica o diez personas naturales directamente afectadas, dentro de los diez días siguientes a la publicación en el D.O. del proyecto sometido a evaluación mediante "dia.". La forma concreta que asumirá este proceso de participación no se encuentra definida en la LBGMA., lo que supone que su determinación quedaría entregada al reglamento (como tantas otras materias que la reforma encomendó a la potestad reglamentaria) y, según el artículo 26, a las Comisiones de Evaluación y al Director Ejecutivo del SEA, gozando en este ámbito la autoridad de un amplio margen de determinación. Además, el artículo 71 letra e) encarga al Consejo de Ministros para la Sustentabilidad, pronunciarse sobre la forma en que se desarrollará la participación en esta sede $^{51}$. En el evento de presentarse modificaciones sustanciales, al igual que en el caso de la evaluación de un "eia.", se debe ordenar la realización de un nuevo proceso de participación. Asimismo, según se señaló, debe entenderse también que habrá lugar al proceso participativo, aunque no se haya solicitado inicialmente, en el supuesto de una modificación sustantiva de la "dia." en el curso de su evaluación. Asimismo, un procedimiento de participación abreviado, por un lapso de diez días, tiene lugar en la evaluación y certificación de conformidad de cumplimiento de la normativa ambiental aplicable al proyecto o actividad sometido al Sistema mediante "dia.", en los términos establecidos por el artículo 18 quater letra $c$ ).

Esta modificación debe celebrarse, pues amplía el ámbito de la participación a las "dia." en casos en que el proyecto afecte a comunidades, superando una de las principales insuficiencias de la LBGMA., como se dirá más adelante.

En los supuestos en que no se ordene la apertura de la fase participativa, además de la posibilidad de impugnar la decisión cuando provoque indefensión (por ser un acto trámite, según el artículo 15 inciso $2^{\circ}$ LBPA..$^{52}$ ),

${ }^{50}$ El supuesto de la norma resalta el carácter de mecanismo de defensa de derechos o intereses de la participación en este ámbito.

${ }^{51}$ Probablemente el reglamento fijará ciertos mecanismos y permitirá a las Comisiones de Evaluación y al Director Ejecutivo el desarrollo de otras formas de participación adicionales, respecto de las cuales el Consejo de Ministros habrá de pronunciarse.

${ }^{52} \mathrm{El}$ precepto dispone: "Artículo 15: Principio de impugnabilidad. Todo acto administrativo es impugnable por el interesado mediante los recursos administrativos de reposición y jerárquico, regulados en esta ley, sin perjuicio del recurso extraordinario de revisión $y$ de los demás recursos que establezcan las leyes especiales. / Sin embargo, los actos de mero trámite son impugnables sólo cuando determinen la imposibilidad de continuar un procedimiento o produzcan indefensión. / La autoridad que acogiere un recurso interpuesto en contra de un acto administrativo, podrá dictar por si misma el acto de reemplazo". Como se señaló, incluso de considerarse que no fuera un acto trámite impugnable, en tal even- 
aquellos en quienes concurra la condición de interesados pueden igualmente formular sus observaciones según las reglas generales, es decir, con independencia de este trámite formal de participación, en ejercicio del derecho que les reconoce el artículo 17 letra f) LBPA. antes comentado. En este último evento, la Administración tiene el deber de considerarlas en la resolución final en tanto constituyen cuestiones propuestas por los interesados que deben ser resueltas en el acto terminal según ordena el artículo 41 LBPA. y el principio conclusivo.

En resumen, la LBGMA. reconoce el derecho a formular observaciones a cualquier persona natural o jurídica en la evaluación de un "eia." y de una "dia.", en la medida que el proyecto genere cargas ambientales. A su vez, por aplicación del estatuto integrador contenido en la LBPA. -plenamente aplicable en la especie por no existir en la LBGMA. disposición en sentido contrario-, los interesados pueden formular sus alegaciones en cualquier momento, se haya o no dispuesto una fase participativa en el procedimiento, y en el evento que ella hubiera tenido lugar, sin que la no participación en ésta les impida formular tales alegaciones (puesto que es una facultad que integra el derecho a audiencia -es decir, se ejerce por tener la condición de interesados- y es independiente del derecho a formular observaciones que le reconoce a toda persona la LBGMA.).

En cuanto a su aplicación, hasta la fecha la interpretación del Ministerio de Medio Ambiente y del SEA es que en tanto no se dicte el reglamento que regule qué proyectos generan cargas ambientales o cuándo esto tiene lugar, la participación en este ámbito no resultaría aplicable. Esta forma de entender el momento de entrada en vigencia del precepto es contraria al criterio sostenido por la Contraloría General en el dictamen No 78.815, de 28 de diciembre de 2010, en que resuelve que la evaluación ambiental estratégica introducida por la Ley No 20.417 a la LBGMA., a pesar de que su regulación queda también entregada a la potestad reglamentaria, es de aplicación inmediata, integrándose con las disposiciones de la LBPA. ${ }^{53}$. Por tanto, en

to su impugnación se reservaría para el acto terminal, dado que los vicios del proceso no impugnables de forma autónoma se impugnan en el acto administrativo que culmina el procedimiento.

${ }^{53}$ Sobre el particular el dictamen precitado establece: "la circunstancia de no haberse publicado el reglamento al cual se remite el artículo $7^{\circ}$ ter de la ley $N^{\circ} 19.300$, no debe impedir que se cumpla con la voluntad del legislador manifestada en sus articulos $2^{\circ}$, letra ibis) y $7^{\circ}$ bis, en orden a que los planes reguladores comunales deben someterse a este procedimiento especial, resultando conveniente agregar en el presente acto, que con la aplicación supletoria de las normas pertinentes de la ley $N^{\circ} 19.880$ en aquél, se evita que los planes normativos de carácter general que producen impacto sobre el medio ambiente o la sustentabilidad, como son los planes reguladores comunales, queden al margen de la normativa 
mi opinión la falta del reglamento no es óbice para la aplicación in actum de la fase participativa en el procedimiento de evaluación de las dias.

d) Participación en el procedimiento de revisión de "rca." Por último, resta mencionar que el legislador establece con carácter preceptiva la realización del periodo de información pública en el supuesto de revisión excepcional, que se inicia de oficio, a petición del titular o del directamente afectado, de una "rca." en el curso de la ejecución del proyecto ante una alteración substancial de las variables evaluadas ${ }^{54}$ (artículo 25 quinquies). En este procedimiento administrativo de revisión, cuya regulación se encarga nuevamente a la potestad reglamentaria, debe considerarse "la información pública del proceso, de conformidad a lo señalado en la ley $N^{\circ} 19.880^{\prime \prime}$, lo cual constituye un acierto de la reforma que esperemos el reglamento no se encargue de opacar. El periodo de información pública, regulado en el artículo 39 LBPA., se compone de una fase informativa y de una participativa y, según dicho precepto, la intervención de la ciudadanía en esta última no atribuye, per se, la condición de interesado ${ }^{55}$.

Adicionalmente, en la iniciación de este procedimiento administrativo especial de revisión se reconoce la intervención del "directamente afectado", esto es, aquellos sujetos distintos del titular (a quien también corresponde legitimación para iniciarlo) a quienes el proyecto les afecta en algún modo. En este procedimiento se debe considerar la "audiencia del interesado", de modo que los directamente afectados harán valer sus alegaciones hasta dicha oportunidad, luego de la cual no puede ser ejercida, según el mismo artículo 25 quinquies LBGMA. en relación con el artículo 17 letra f) LBPA.

que los obliga a incorporar las consideraciones ambientales de desarrollo sustentable en su formulación o en sus modificaciones sustanciales".

${ }^{54}$ Este es otro acierto de la reforma, pues aunque se intentaba defender su procedencia en la práctica, las dificultades tanto para los solicitantes, para la Administración como para el proponente, así como la necesidad de resguardar la seguridad jurídica en la intangibilidad de la "rca.", dificultaban su procedencia.

${ }^{55}$ En la faz informativa del mecanismo, la entidad administrativa da a conocer a la ciudadanía, mediante una publicación en el Diario Oficial o en un diario de circulación nacional, la existencia del procedimiento, anunciando que cualquier persona puede examinar el expediente o las partes que de él indique. Se trata, por tanto, de una etapa de carácter informativo que viene a materializar el principio de publicidad del procedimiento y que no difiere en lo sustantivo del régimen común de acceso a la información pública, salvo por la obligación de la autoridad de anunciar la apertura del período de información, lo que permite a la ciudadanía enterarse de la existencia del procedimiento. La dimensión participativa del mecanismo permite a los ciudadanos, sean o no interesados, formular observaciones en un plazo que se determina en el acto que ordena el trámite y que no puede ser inferior a diez días hábiles. 


\section{Derecho a obtener respuesta fundada de las observaciones.}

Respecto del derecho de obtener respuesta fundada de las observaciones formuladas, que constituye el tercer peldaño del derecho de participación ambiental, los artículos 29 y 30 bis disponen que el SEA debe considerar las observaciones como parte del proceso de calificación y hacerse cargo de ellas en su resolución. Dicha resolución debe estar disponible en la página web del servicio con a lo menos cinco días de anticipación a la calificación del proyecto. La reforma incidió en dos aspectos. En primer término, modificó la redacción anterior que obligaba a la Administración a ponderar en los fundamentos de la resolución dichas observaciones y la sustituyó por el deber de considerarlas y hacerse cargo de ellas, pronunciándose fundadamente respecto de todas ellas, lo que, al menos nominalmente, pretendería dar mayor incidencia a la participación ${ }^{56}$, aunque en realidad no constituye un avance sustantivo en la clarificación de los criterios al efecto. En segundo término, se modifica la operativa actual de que las observaciones eran ponderadas en la "rca.", pues ahora este pronunciamiento debe hacerse en una resolución distinta que es un acto trámite que ha de servir de fundamento al acto terminal del procedimiento de calificación y que, en tal carácter, tiene que estar disponible con anterioridad. Además de esta modificación, la Ley No 20.417 dispuso en su artículo 9 bis inciso $1^{\circ}$ como contenido del Informe Consolidado de Evaluación "la evaluación técnica de las observaciones planteadas por la comunidad y los interesados". Como se aprecia, el precepto reconoce expresamente la posibilidad de que, además de las observaciones ciudadanas producto de la fase participativa, existan observaciones deducidas por interesados distintos del titular, lo que refuerza los planteamientos principales de este trabajo ${ }^{57}$. Por último, el artículo 36 RSEIA. señala también como contenido u objeto de la "rca." la "ponderación de las observaciones formuladas por las organizaciones ciudadanas con personalidad juridica y por las personas naturales directamente afectadas" 58 .

En caso de estimarse por los participantes que las observaciones no han sido debidamente consideradas en los fundamentos de la "rca." (ya sea porque no fueron consideradas en el acto trámite que sobre ellas se pronuncia o bien porque, habiéndolo sido, la" rca." omite referirse a ellas), se mantiene la posi-

${ }^{56}$ Hervé, Dominique, cit. (n. 4), p. 282.

${ }^{57}$ En este mismo sentido, el artículo 86 inciso 2 LBGMA. dispone que el acta de evaluación que elabore el Comité Técnico de Evaluación será “de libre acceso a los interesados", lo que no deja lugar a dudas de la posibilidad de que al procedimiento concurran interesados distintos del titular solicitante.

${ }^{58}$ Esta última disposición deberá ser adecuada a la reforma cuando se modifique el RSEIA. en el sentido de considerar el cambio de redacción (cualquier persona) y agregar a los interesados, como indica el artículo 9 bis LBGMA. recién comentado. 
bilidad de reclamar, pero desaparece el recurso de reclamación especial ante la autoridad superior contenido originalmente en la LBGMA. En cambio, los participantes disponen del recurso de reclamación general contenido en el artículo 20 cuyo conocimiento corresponde al Director Ejecutivo del SEA, en el evento que se trate de la evaluación de una "dia.", o a un Comité de Ministros, tratándose de la evaluación de un "eia." (en la práctica, el recurso se interpone ante el director ejecutivo del SEA en Santiago, aunque la ley no lo establece). Este recurso administrativo ad hoc debe interponerse en el plazo de treinta días desde la notificación de la resolución recurrida -lo que refuerza una vez más la obligación de la Administración de notificar la "rca." a los participantes-, y su interposición no suspende los efectos del acto impugnado, como se consagraba antes de las reforma en estudio. Ello no impide que, previa solicitud, la Administración pueda ordenar la suspensión del acto en tanto el recurso no sea resuelto en definitiva ${ }^{59}$. Como señalaba la doctrina y el propio RSEIA. ${ }^{60}$, en caso de acogerse el recurso el efecto no era su anulación, sino la modificación de la "rca." en el sentido de la debida consideración de las observaciones. Sin embargo, en mi opinión, si producto de no haberse considerado todas las observaciones en el procedimiento de evaluación, la autoridad que resuelve el recurso (director ejecutivo del SEA o Comité de Ministros) advierte que producto de tales observaciones resulta necesario alterar la calificación del proyecto, se encuentra plenamente facultada para modificar la resolución, ya sea estableciendo nuevas medidas para hacer frente a los impactos del proyecto o, incluso, para disponer la calificación negativa del proyecto o actividad. Si así no fuera, es decir, si el objeto del recurso fuera sólo modificar la "rca." para resolver que se consideran las observaciones sin que ello tenga ningún efecto en la calificación, la participación de la ciudadanía no tendría en realidad ningún sentido, pasando a ser una mera declaración de principios; debe recordarse que el

${ }^{59}$ En contra se pronunciaba Astorga, respecto del recurso especial anterior a la modificación legislativa, quien señalaba que no era procedente la orden de no innovar en la sede administrativa ni judicial. Astorga, Eduardo, Sistema, cit. (n. 12), pp. 87-88. En mi opinión, ello no es acertado toda vez que la LBGMA. sólo indica que la interposición del recurso no suspende (de pleno derecho debe entenderse) los efectos del acto, pero nada impide que se solicite a la Administración su suspensión y que ésta la disponga. Por lo demás, el artículo 3 inciso final LBPA. reconoce expresamente a la autoridad la facultad de disponer una orden de suspensión del acto en la fase recursiva y a la justicia conociendo en sede contencioso-administrativa.

${ }^{60} \mathrm{El}$ artículo 46 inciso 5 del RSEIA. dispone: "Sólo si el recurso es acogido, la resolución respectiva ponderará debidamente las observaciones presentadas por las organizaciones ciudadanas y por las personas naturales a que se refiere el articulo 28 de la Ley. Si el recurso es rechazado, declarará que las observaciones fueron debidamente ponderadas en la resolución reclamada". 
objeto de la participación es permitir que la Administración resuelva conforme a elementos aportados también por la ciudadanía (que ellas sirvan de fundamento a la decisión final).

De lo resuelto por el director ejecutivo o por el Comité de Ministros, puede reclamarse dentro de treinta días desde su notificación al Tribunal Ambiental ${ }^{61}$, reclamación que puede interponer tanto la ciudadanía como el titular del proyecto. Como puede advertirse, si bien las observaciones deben considerarse y resolverse en un acto anterior (acto trámite), la impugnación se produce respecto de la "rca." (acto terminal), lo que confirma lo señalado en cuanto a que los defectos de tramitación que no son impugnables de forma autónoma, se impugnan en la resolución final.

Las ventajas de la modificación legislativa en este punto son, por una parte, que se extiende el plazo para recurrir (treinta días versus los quince anteriores) y que, por la otra, a diferencia del recurso anterior cuya resolución por la autoridad superior no era recurrible ante la Justicia ordinaria -a diferencia de lo que sucedía cuando se resolvía negativamente el recurso de reclamación deducido por el titular del proyecto, quien podía reclamar ante el juez civil de acuerdo con el procedimiento contenido en el artículo 60-, a partir de la reforma la resolución que desestima el recurso deducido por quienes participaron es recurrible ante el Tribunal Ambiental ${ }^{62}$. Así, el principio de impugnabilidad del acto administrativo reconocido en la LBPA. se vio reforzado respecto de la ciudadanía, cuestión que debe celebrarse.

Respecto de los interesados que formularon alegaciones, haya habido o no periodo de participación y hayan o no participado, la Administración se encuentra también obligada a considerar y resolver dichas observaciones, de acuerdo al artículo 17 letra f) antes citado y artículo 41, ambos de la LBPA. $^{63}$. Si el acto terminal no se pronuncia sobre estas alegaciones, habrá un vicio en la motivación del acto, en su contenido y una infracción a los principios de inexcusabilidad, conclusivo y contradictoriedad ${ }^{64}$, que podrán motivar la anulación del acto por la propia Administración (mediante los

${ }^{61}$ En tanto no entre en vigencia la ley que crea este Tribunal especial, y de conformidad con lo dispuesto por el artículo décimo transitorio de la Ley $\mathrm{N}^{\circ} 20.417$, su conocimiento corresponde al juez de letras en lo civil.

${ }^{62}$ Véase la n. 61.

${ }^{63}$ Este último precepto dispone: "Artículo 41. Contenido de la resolución final. La resolución que ponga fin al procedimiento decidirá las cuestiones planteadas por los interesados".

${ }^{64}$ En este sentido la Contraloría, en dictamen No 4.046, de 25 de enero de 2005, precisó: "la interpretación elaborada por el Servicio priva en los hechos a terceros potencialmente afectados con la solicitud, de apreciar las razones técnicas que justificarian la adopción de dicha medida y eventualmente formular descargos que desvirtúen las conclusiones de esos informes dentro del plazo que el artículo 132 del Código de Aguas prevé al 
recursos administrativos ordinarios o el procedimiento de invalidación regulado en el artículo 53 LBPA.) o a través del ejercicio de las demás vías de impugnación ${ }^{65}$.

\section{CRÍticas a la PARTICIPACIÓN CIUDADANA}

EN EL SISTEMA DE EVALUACIÓN DE IMPACTO AMBIENTAL

Sobre la participación ciudadana en el procedimiento de evaluación de impacto ambiental pueden formularse varias observaciones críticas. Parte importante de éstas han sido recogidas y subsanadas en la comentada modificación introducida por la Ley No 20.417, según pasa a revisarse.

\section{Deficiencias subsanadas por la Ley $N^{\circ} 20.417$.}

a) Inexistencia de participación en el procedimiento de evaluación de las dias. Como una primera cuestión corresponde señalar que la LBGMA. en su versión original consideraba la participación en el "seia" sólo respecto de aquellos proyectos o actividades que se sometían mediante "eia.", y no, en cambio, si su ingreso se realizaba por "declaración" ${ }^{66}$. La exclusión de la intervención de la comunidad respecto de este último instrumento se justificaba teóricamente debido a que los proyectos o actividades que se sometían al "seia" por "dia." tenían escaso impacto ambiental, sobre todo respecto de la comunidad. A su vez, la "dia." originalmente era una declaración jurada del titular en cuanto a que el proyecto cumplía con la normativa ambiental y, en caso que durante su ejecución se verificaran incumplimientos, el efecto normal era la revocación de la licencia administrativa ${ }^{67}$. En consecuencia, los proyectos o actividades de mayor relevancia son los que

efecto, derecho que es una manifestación del principio de contradictoriedad consagrado en el artículo $10^{\circ}$ de la Ley $N^{\circ} 19.880^{\prime \prime}$.

${ }^{65}$ Véase la n. 85.

${ }^{66} \mathrm{~A}$ pesar de que el proyecto original de LBGMA. enviado por el Ejecutivo sí consideraba la participación de la comunidad organizada en la evaluación de las "dias." La Comisión de Recursos Naturales, Bienes Nacionales y Medio Ambiente del Senado excluyó tal intervención por "estimarse innecesaria”. Cfr. Moreno, Carlos, cit. (n. 5), p. 74. Sin embargo, incluso antes de la dictación de la Ley No 20.417, la misma Comisión informó favorablemente en enero de 2009 respecto de una moción que pretendía modificar la LBGMA. para establecer la participación respecto de las "dias.".

${ }^{67}$ Por ello, Del FÁvero, Gabriel, Ley sobre bases generales del medio ambiente, en Estudios Públicos, 54 (Santiago, otoño de 1994), p. 3, comentando la recién dictada LBGMA. en 1994, señalaba que la "dia." era una "fórmula rápida aplicable a proyectos cuyas actividades están suficientemente regladas por normas". En la práctica ello no resultó ser en absoluto así. 
presentarían alguna de las características definidas en el artículo 11 LBGMA. y, por consecuencia, ingresarían al sistema mediante "estudio".

Sin embargo, como suele suceder, la teoría se divorciaba completamente de la práctica. En efecto, la práctica recurrente era que los titulares de proyectos ingresaban al "seia" mediante "dia.", entre otras cosas, precisamente para evitar el trámite de la participación ciudadana, aunque se tratara de proyectos de un intenso impacto a la comunidad. Para ilustrar lo expresado, basta considerar que del total de proyectos sometidos al "seia” al año 2007, 10.734 lo hicieron a través de "declaración”, en tanto que sólo 655 vía "eia."68. Tal práctica, que ha distorsionado el sentido original de la "dia." (por haber transformado su contenido prácticamente en un "pequeño "eia."), había restringido considerablemente la participación ciudadana en la evaluación del impacto ambiental de proyectos ${ }^{69}$. Como una especie de paliativo a tal

${ }^{68}$ CONAMA, El desafio del medio ambiente en Chile (Santiago, 2007), p. 11. De hecho, entre abril de 1997 e igual periodo de 1998 (es decir, ya durante el primer año de la implementación obligatoria del Sistema), el 86\% de los proyectos había ingresado mediante Del FÁvero, Gabriel - Katz, Ricardo, Resultados y consecuencias del sistema chileno de evaluación de impacto ambiental ("seia"), en Estudio Públicos, 73 (Santiago, verano de 1999), p. 376. La Contraloría, en dictamen No 50.465, de 24 de octubre de 2006, ha señalado que la "dia." es la regla general: "Al respecto, la jurisprudencia administrativa de esta Contraloria General -contenida entre otros en los dictámenes $N^{\circ}$ s 6.438 y 12.631, ambos de 2006-, ha precisado que conforme a lo establecido en el articulo 11 de la referida ley y en los artículos $4^{\circ}$ y siguientes del reglamento citado, la regla general es que un proyecto o actividad sometido al Sistema debe contar con una Declaración de Impacto Ambiental, salvo que genere o presente a lo menos uno de los efectos, caracteristicas o circunstancias que enumeran y desarrollan dichos preceptos, en cuyo caso requerirá la elaboración de un Estudio de Impacto Ambiental, determinación que corresponde a la autoridad ambiental competente, en su calidad de órgano técnico especializado al que se le asigna la administración del Sistema de Evaluación de Impacto Ambiental, conforme al artículo $8^{\circ}$ de la Ley $N^{\circ} 19.300^{\prime \prime}$. La interpretación es cuestionable dado que, si fuera la regla general -y si en esto hubiera una regla general-, el titular no debiese demostrar que el proyecto no presenta las características y efectos que hacen procedente el ingreso mediante "eia".

${ }^{69}$ Antes de la modificación y con el objeto de poner remedio a esta situación, el Diputado Antonio Horvath Kiss presentó una moción (Boletín 5.483-12) que pretendía modificar la LBGMA., para establecer la participación ciudadana respecto de la "dia.". El plazo para formular observaciones que proponía la moción era de veinte días. En la misma línea, la moción (Boletín 5.132-12) presentada en 2007 por los diputados Guillermo Ceroni, Guido Girardi, Rodrigo González. Patricio Hales, Jorge Insunza, Adriana Muñoz, Jaime Quintana, Laura Soto, Eugenio Tuma y Esteban Valenzuela, buscaba modificar el artículo 26 LBGMA., incorporando el siguiente inciso: “Asimismo, la Comisión Nacional o Regional de Medio Ambiente según corresponda, podrá decretar la realización de un proceso de participación ciudadana, en aquellos proyectos cuya Declaración de Impacto Ambiental se encuentre en evaluación, siempre que lo soliciten a 
deficiencia, el artículo 30 LBGMA. establecía diversas medidas de publicidad: la CONAMA o las COREMA, según correspondiera, debía publicar mensualmente en el Diario Oficial un listado de los proyectos o actividades que se sometieron al "seia" en el mes anterior mediante "dia.", lo que en teoría permitía mantener informada a la ciudadanía de esta clase de ingreso al Sistema, aunque ello no suponía reconocer una fase participativa en el procedimiento. El referido listado de proyectos, según el artículo 31 LBGMA., así como el listado o extracto publicado en el Diario Oficial de los proyectos sometidos al "seia" mediante Estudio, debían remitirse por la misma Administración a las municipalidades en cuyo territorio se desarrollaría el proyecto o actividad, medida de publicidad que conservó la Ley No 20.417. Asimismo, según el artículo 52 RSEIA., en las oficinas de la municipalidad y en las del Secretario de la COREMA (dirección regional de CONAMA) o del director ejecutivo de la CONAMA, en su caso, debía exhibirse en un lugar público el extracto. Esta información se veía reforzada por la plataforma en Internet del "seia", que permite acceder a los expedientes administrativos por proyecto o actividad, por región y por tipo de proyecto, lo que constituía una importante vía de acceso a la información ambiental, y ahora por el registro público de "rca." que debe mantener la Superintendencia del Medio Ambiente en su sitio web, según el artículo 25 quáter LBGMA.

En consecuencia, el mayoritario sometimiento de los proyectos y actividades al Sistema mediante "dia.", había restringido en demasía el ámbito de la participación ciudadana en el procedimiento de evaluación ambiental, afectando tanto el cumplimiento del deber de los órganos del Estado de facilitar la participación de la ciudadanía en materia ambiental, como los principios de contradictoriedad e imparcialidad del procedimiento administrativo. Reconociendo ese desolador panorama, la Ley No 20.417 da un importante giro estableciendo la acertada regla que permite la participación en la evaluación de la "dia." en los términos antes comentados (es decir, cuando el proyecto genera cargas ambientales). Lo relevante ahora es que el Reglamento no restrinja los supuestos de procedencia de esta fase del procedimiento y que las autoridades le den una aplicación efectiva cuando las circunstancias lo ameriten, de modo que no se trate de una simple norma programática. En esta materia, la interpretación del supuesto de procedencia debe ser extensiva, pues se aviene mejor con el derecho a participar que reconoce la LBGMA. (interpretación pro cive).

lo menos dos organizaciones ciudadanas con personalidad jurídica, a través de sus representantes, o como minimo diez personas naturales directamente afectadas. Esta solicitud deberá hacerse por escrito y presentarse en la Comisión Nacional o Regional de Medio Ambiente respectiva, dentro del plazo de 30 dias, contados desde la publicación en el Diario Oficial del proyecto sometido a Declaración de Impacto Ambiental de que se trate". 
b) Participación restringida a una fase inicial del procedimien to: Otro de los aspectos recurrentemente criticados era que, según la regulación original, la participación de la comunidad se desarrollaba únicamente en la etapa inicial de la evaluación ambiental ${ }^{70}$. En efecto, una vez presentado el Estudio por el titular del proyecto o actividad, los órganos con competencia ambiental podían formular observaciones y solicitar aclaraciones, rectificaciones o ampliaciones del mismo. Una vez notificado de éstas, el titular del proyecto podía dar respuesta a esas observaciones y formular las aclaraciones, rectificaciones y ampliaciones pertinentes e introducir modificaciones al proyecto a través de addenda. La evaluación definitiva se efectuaba no sólo respecto del proyecto original contenido en el "eia.", sino también sobre las adendas presentadas por su titular, las que solían ser más de una y terminaban modificando en algunos casos sustancialmente el proyecto original. Sin embargo, la participación de la ciudadanía tenía lugar únicamente respecto del original “eia." y no de sus addenda ${ }^{71}$. Esta situación afectaba las bondades de la participación como medio de defensa de derechos e intereses, así como también la posibilidad de que la Administración se nutriera de las opiniones de la ciudadanía, pues la temprana intervención no permitía formular observaciones completas. Esta configuración original de la participación en la fase inicial del procedimiento afectaba el principio de contradictoriedad, que supone que los afectados puedan formular sus apreciaciones contando con todos los elementos necesarios al efecto ${ }^{72}$, aunque ello no impedía, como se ha señalado, que aquellos en quienes concurriera la condición de interesados formularan observaciones en una fase posterior. La apertura de un nuevo periodo participativo frente a modificaciones sustanciales del proyecto introducido por la Ley No 20.417, viene a subsanar esta deficiencia.

c) Ejecución anticipada del proyecto o actividad: Se criticaba también que la LBGMA. permitía iniciar la ejecución de un proyecto aún antes de contar con la "rca.", presentando al efecto una póliza de seguro que cubriera los eventuales daños al entorno, lo que presuponía erradamente

${ }^{70}$ Me unier, Pamela, La participación ciudadana en el sistema de evaluación de impacto ambiental chileno, en VV. AA., Prevención y solución de conflictos ambientales: Vias administrativas, jurisdiccionales y alternativas. Actas de las Segundas Jornadas de Derecho Ambiental (Santiago, LexisNexis 2004), p. 67.

${ }^{71}$ En la práctica, gran parte de los proyectos presenta dos o más addendas, variando de esta forma los términos originales sobre los cuales se pronunció la ciudadanía.

${ }^{72}$ Como indica Royo Villanova, Segismundo, cit. (n. 19), p. 64: "El interesado ha de tener a la vista todas las actuaciones administrativas para poder alegar lo que estime pertinente en defensa de sus derechos, y por eso interesa también a la Administración conocer las alegaciones hechas por el interesado con pleno conocimiento de causa, antes de formular el dictamen o propuesta”. 
que el daño ambiental era siempre reversible y reparable económicamente ${ }^{73}$. En este evento, el proyecto se desarrollaba con una autorización provisoria que no había considerado la participación de la ciudadanía, sin perjuicio de que ésta tuviera lugar en el curso del procedimiento de evaluación del "eia." Esta situación fue suprimida por la Ley $N^{\circ} 20.417$ que derogó el inciso 2 del artículo 15 , lo cual constituye otro acierto de la modificación legislativa.

\section{Deficiencias no subsanadas por la reforma y criticas a la Ley $N^{o}$} 20.417 .

a) Ausencia de definición de criterios de consideración de las observaciones: Una primera cuestión deficitaria que no fue subsanada, como apuntaba Eduardo Astorga antes de la reforma, era la falta de transparencia y regulación de los criterios de ponderación de las observaciones de la ciudadanía, lo que constituía a su juicio una de las principales deficiencias del sistema ${ }^{74}$. En la práctica, muchas veces la Administración respondía las observaciones con formulas sacramentales preestablecidas que en poco o nada aportaban al proceso, reiterando, por ejemplo, que "el aspecto observado por la ciudadanía había sido evaluado por los órganos con competencia ambiental" o que era "pertinente y la observación es acogida". Podía advertirse también que en muchas oportunidades la respuesta a las observaciones era una remisión a cierto capítulo o informe ambiental del proceso de evaluación, lo que reafirma que parte importante de los conflictos ambientales surge producto de problemas de información y de entendimiento (es decir, a pesar de la disponibilidad de la información, ya sea por su volumen, complejidad técnica u otra causa, su comprensión resulta dificultosa). En otros casos, las observaciones permitían a la Administración considerar elementos no advertidos en el proceso de evaluación, pero debido a su tardía ponderación, muchas veces no tenían el efecto esperado. Al menos a partir de la reforma, las observaciones deben ser consideradas y resueltas con antelación a la calificación final, lo que teóricamente da cierto margen a la Administración en caso de advertir gracias a las observaciones de la ciudadanía, cuestiones no visualizadas.

b) Desigualdad de los intervinientes. En el mismo sentido se ha criticado la configuración de este mecanismo en cuanto la ciudadanía estaría en una posición de desventaja estructural respecto de la autoridad y el proponente, pues carece de los medios y recursos necesarios para fundar adecuadamente sus observaciones, especialmente cuando se trata de comunidades

${ }^{73}$ Moreno, Carlos, cit. (n. 5), p. 83.

${ }^{74}$ Astorga, Eduardo, Derecho ambiental chileno (Santiago, LexisNexis 2007), p. 233. 
de condición socioeconómica baja y de personas naturales no asociadas ${ }^{75}$. Ello, sumado al acotado plazo para formular las observaciones, no favorece el ejercicio de este mecanismo participativo, sobre todo respecto de individuos no asociados. Para equilibrar esta situación, algunos sistemas comparados consideran financiamiento estatal a los participantes, de modo de procurar una igualdad de oportunidades en la participación de la ciudadanía, del proponente y de los evaluadores. Este estado de cosas no fue alterado por la reforma, de modo que subsiste como una de las principales deficiencias del Sistema, reconociendo eso sí, que es un problema de difícil solución ${ }^{76}$.

c) Carácter consultivo de la participación: Quizás el aspecto más criticado es la naturaleza consultiva de la participación, por cuanto la Administración no se encuentra vinculada por las observaciones de la ciudadanía. En mi opinión, la operatoria del sistema impide asignarle tal carácter vinculante a la participación, pues si así fuera, se estaría trasladando el centro de la decisión a la ciudadanía; es decir, la decisión le correspondería ésta y no a la Administración. El problema de ello es que es la Administración la encargada de adoptar decisiones que atiendan al interés general y, por ende, quien tiene a su cargo la tarea de equilibrar los distintos intereses en ocasiones contrapuestos (normalmente producidos por una pugna entre el derecho a vivir en un medio ambiente libre de contaminación, el derecho a desarrollar actividades económicas y el derecho de propiedad, además del deber del Estado de velar por la preservación de la naturaleza y por el incremento del patrimonio cultural). De este modo, si las observaciones fueran vinculantes, la decisión la estaría adoptando una de las partes del procedimiento (que representa un interés) y no una entidad imparcial que equilibre los intereses en juego ${ }^{77}$. Ello supone, por lo mismo, que en la decisión que debe corres-

${ }^{75}$ Moreno, Carlos, cit. (n. 5), p. 83.

${ }^{76} \mathrm{Si}$ bien las ongs ambientales en ocasiones recurren al financiamiento a través de fondos internacionales que fomentan la asociatividad y la defensa del entorno, la deficiencia se agudiza tratándose de personas no asociadas, que generalmente contarán con menores medios para emprender una participación en una materia técnica y en ocasiones de sumo compleja.

${ }^{77}$ En este sentido, la Contraloría, en dictamen $N^{\circ}$ 60.170. de 19 de diciembre de 2008, ha rechazado la posibilidad de someter a plebiscito comunal (participación vinculante) la instalación de centrales hidroeléctricas por no tratarse de una materia susceptible de plebiscito, en cuanto no sería de competencia municipal. Sin embargo, en dictamen $\mathrm{N}^{\circ} 41.283$, de 1 de septiembre de 2008 , precisó que era factible que la municipalidad convocara a encuestas o sondeos de opinión (participación consultiva), aunque la materia no fuera de competencia municipal. Por su parte, la Corte Suprema, en sentencia de fecha 14 de octubre de 2010, rol No 4.078-2010 (considerando $2^{\circ}$ ), ha sostenido que la participación ciudadana -refiriéndose a la que corresponde a los pueblos indígenas según el Convenio № 169- sólo puede tener carácter consultivo, pues 
ponder a la Administración, ésta considere los distintos planteamientos de los interesados.

d) Inexistencia de recurso especial para impugnar la "rca." Otro de los aspectos sumamente criticados era que, en caso de rechazo del proyecto o cuando se imponían condiciones que no conformaban a su titular, éste contaba con un recurso especial de reclamación ante el director ejecutivo de la CONAMA o ante el Consejo Directivo. Como se indicó en párrafos anteriores, si dicho recurso administrativo era desestimado, el titular podía recurrir a la justicia ordinaria en procedimiento sumario reglado entonces en los artículos 60 ss. LBGMA. En cambio, en caso que el proyecto fuera calificado favorablemente, la ciudadanía afectada carecía de legitimación activa para deducir el referido recurso administrativo y, menos entonces, para ejercer el reclamo jurisdiccional del antiguo artículo $60^{78}$. El paliativo ante estas situaciones venía dado por el ejercicio de la acción constitucional de protección, la cual, a pesar de todas las restricciones que reconoce en la materia, se erigió como un importante mecanismo de control judicial de las $\mathrm{RCAs}^{79}$. Cuando se invocaba el derecho a vivir en un medio ambiente libre de contaminación (artículo 19 № 8 C.Pol.), esas restricciones se referían principalmente a la titularidad del derecho ${ }^{80}$, a la legitimación activa ${ }^{81}$, a la

"jamás dicha forma de participación podría constituirse en una consulta popular vinculante ni afectar las atribuciones privativas de las autoridades que la Carta Fundamental determina. La soberania, conforme lo dispuesto en el articulo $5^{\circ}$, reside esencialmente en la Nación y se ejerce a través del plebiscito y elecciones periódicas y por las autoridades que la propia Constitución establece, y 'ningún sector del pueblo ni individuo alguno puede atribuirse su ejercicio".

${ }^{78}$ Dado que la reclamación judicial se producía contra la resolución que desestimaba el recurso administrativo de reclamación. Es decir, era una acción judicial que, por decirlo de alguna forma, exigía el agotamiento de la vía administrativa.

${ }^{79} \mathrm{El}$ primer recurso de protección en materia ambiental acogido fue interpuesto por CODEFF y correspondió al “caso Lago Chungará”, ubicado en el altiplano de Arica. Astorga, Eduardo, Sistema, cit. (n. 12), p. 82.

${ }^{80}$ Que en cuanto derecho a vivir en un entorno libre de contaminación sólo corresponde a personas naturales y no entes jurídicos o morales. Asimismo, se exigía que el recurrente viviera en un lugar adyacente al ambiente afectado (teoría de entorno adyacente).

${ }^{81}$ En las ocasiones en que no se cuestionó la titularidad del derecho, se discutió si personas jurídicas como corporaciones de defensa del ambiente tenía interés suficiente para ejercer la acción. En ocasiones la legitimación fue aceptada, como en el razonamiento respecto de la intervención del Comité Nacional Pro Defensa de la Fauna y Flora en el "caso Stutzin", en 1997 (confirmada por sentencia de la Corte suprema, de 23 de septiembre de 1997): "En lo que respecta al Comité Nacional Pro Defensa de la Fauna y de la Flora, dada la naturaleza de la actividad de dicha institución que se desprende de su propia denominación, no merece reparo que haga valer una acción de rango 
aptitud de un acto administrativo para producir la afectación de la garantía ${ }^{82}$, a la deferencia administrativa ${ }^{83}$ y a que la afectación excluía la posibilidad de recurrir por amenazas al derecho ${ }^{84}$.

En este aspecto no hubo ningún avance, de modo que se mantiene a la ciudadanía e incluso a los interesados que pueden ser afectados con el proyecto, sin la posibilidad de impugnar la "rca." mediante el recurso especial de reclamación ${ }^{85}$. En mi opinión, esta situación resulta contraria al principio de contradictoriedad e igualdad de las partes ante el procedimiento, dado que el

constitucional con el propósito de que la naturaleza y el medio ambiente sean debidamente preservados". Véase: GuZMán, Rodrigo, La regulación constitucional del ambiente en Chile. Aspectos sustantivos y adjetivos (Santiago, LexisNexis 2005), pp. 236-237.

${ }^{82}$ Esta última era el argumento de defensa de la Autoridad Ambiental, que sostenía que la eventual afectación al derecho, de provocarse, sería por la ejecución material del proyecto y no por la "rca.". Sin embargo, la actuación material tenía por título precisamente ese acto administrativo y al menos amenazaba esa garantía. Por lo demás, de aceptarse esa línea de defensa y de recurrirse contra la ejecución material del proyecto, su titular podría alegar que el proyecto fue autorizado por la "rca." y que el plazo de interposición de la acción en su contra ya se habría extinguido.

${ }^{83}$ Los Tribunales superiores reconocían a la COREMA o CONAMA un grado de discrecionalidad técnica en la decisión que no podían sustituir, dado que era imposible para las Cortes reproducir todo el iter procedimiental para arribar a una resolución. Este recurso a la deferencia administrativa tiene mucha lógica respecto de los elementos políticos de la decisión, pero debe ceder cuando se está en presencia de vicios en el procedimiento que sean invalidantes. Además, tampoco puede excluir el control de los hechos, ni en el supuesto que se tratara de una potestad discrecional -cosa que es sumamente cuestionable-, la Justicia siempre puede controlar los elementos reglados del acto.

${ }^{84}$ Interpretación estrecha y literal del texto constitucional que no se aviene con la regla de interpretación in fao libertatis ni con el principio preventivo que exige adoptar medidas ante potenciales eventos dañosos al entorno, sin que sea preciso esperar su materialización (por lo demás, muchas veces consumado el daño es irreparable o esa reparación tarda mucho).

${ }^{85}$ Con todo, ello no significa que la ciudadanía se encuentre desprovista de vías administrativas y judiciales -adicionales e independientes a la acción de protecciónpara impugnar la resolución. En efecto, como se ha señalado, aquellos ciudadanos que puedan resultar afectados con el acto terminal, esto es, que tienen la condición de interesados en el procedimiento, son titulares de los recursos administrativos que el ordenamiento les reconoce de acuerdo con el principio de impugnabilidad de la actuación de los órganos de la Administración del Estado. Así, los interesados dispondrán del recurso de reposición que le reconoce el artículo 10 LBGAE. y el artículo 54 LBPA. Asimismo, podrá solicitar la invalidación del acto ante la propia autoridad que lo dictó (según el artículo 53 LBPA., ejercer el recurso de revisión, por ejemplo, cuando el acto se dictó sin el debido emplazamiento (artículo 60 LBPA.), solicitar un pronunciamiento de Contraloría mediante la petición de dictamen, deducir la acción de nulidad de Derecho público, la acción constitucional de protección, entre otros. 
solicitante es un interesado al igual como lo son aquellos que se verán afectados con la resolución final. Además, la inexistencia de recurso especial de reclamación fuerza la judicialización -normalmente mediante el ejercicio de la acción de protección-con los inconvenientes que para todas las partes ello supone. En cambio, como apunta el profesor Paulo Leme: "La participación en la interposición de recursos administrativos es fundamental para que haya la posibilidad de que los interesados abran las puertas de la propia Administración para que ella revise sus actos irregulares. El recurso administrativo implica una conciliación y corrección del acto administrativo ambiental, evitándose la interposición de acciones judiciales" ${ }^{\$ 6}$. Desde esta óptica, no se vislumbra una justificación suficiente para atribuirle legitimación a uno de los interesados en este recurso especial, y negársela a los otros ${ }^{87}$.

e) Insuficiencia del plazo para formular observaciones. El término de sesenta días para que la ciudadanía formulara observaciones al "eia." era también considerado insuficiente ${ }^{88}$. Y no obstante la LBGMA. permite suspender el plazo de evaluación de común acuerdo entre el titular del proyecto y la autoridad ambiental, CONAMA había entendido que dicha suspensión no afectaba el término para formular observaciones, el que no se suspendía por ser otro procedimiento dentro del "seia" distinto a la evaluación del proyecto ${ }^{89}$, interpretación bien particular que esperemos sea revisada por la nueva Institucionalidad. Este periodo se mantiene en iguales términos respecto del "eia." luego de la reforma, y considera veinte días para la participación en la evaluación de las dias., salvo el procedimiento

${ }^{86}$ Leme, Paulo, cit. (n. 11), p. 105.

${ }^{87} \mathrm{Si}$ bien se entiende que el procedimiento está destinado a producir una resolución favorable al proyecto, el privar de este recurso administrativo lo que hace en definitiva es restringir las posibilidades de que la aprobación o rechazo sea resuelta en sede administrativa, dado que los demás interesados no dispondrán de esta vía recursiva administrativa y deberán recurrir directamente a la Justicia, sin perjuicio de los otros medios de impugnación de que pueden ser titulares.

${ }^{88} \mathrm{~A}$ objeto de subsanar esta deficiencia, una moción (Boletín 4.518-12), presentada el año 2006, por los Diputados Ramón Barros, Sergio Bobadilla, Enrique Estay, Marcelo Forni, Javier Hernández, Juan Lobos, Iván Moreira, Iván Norambuena, Manuel Rojas, y Felipe Ward, pretendía modificar la LBGMA., ampliando el plazo para formular observaciones en los "eia." a noventa días. Con todo, recientemente y a propósito de la evaluación del proyecto Hidroaysén, la ciudadanía presentó más de 11.000 observaciones, gracias a una potente campaña liderada por el Consejo de Defensa de la Patagonia. Fundación Terram, Balance Ambiental. 2008 (Santiago, 2008), p. 2.

${ }^{89}$ Criterio sostenido por CONAMA en Ordinario D. J. No 014734, de 24 de octubre de 2001. En el ordenamiento colombiano, por ejemplo, el periodo de participación -que se verifica a través de una audiencia pública- suspende los plazos del procedimiento. Padilla, Eduardo, Lecciones de Derecho ambiental (Santa Fe de Bogotá, Leyes, 2000), p. 486. 
abreviado de participación en que se reduce a diez días. En defensa del plazo puede señalarse la necesidad de acotar la duración total del procedimiento de calificación ambiental, considerando que la etapa de participación ciudadana es una de las fases del íter procedimental y no la única, y la necesidad de observar los principios de celeridad, eficiencia y eficacia en la actividad administrativa ${ }^{90}$.

f) Eliminación de CORES. De acuerdo con el original artículo 81 LBGMA, las COREMAS se integraban, entre otros miembros, por cuatro consejeros regionales elegidos por el respectivo Consejo Regional (CORE). Esta forma de integración permitía considerar de alguna forma los aspectos sociales en la decisión, puesto que según el artículo 28 de la Ley No 19.175: Orgánica Constitucional sobre Gobierno y Administración Regional, la finalidad del CORE es hacer efectiva la participación de la comunidad regional. De esta forma, los consejeros regionales que integraban la COREMA, a pesar de ser electos de forma indirecta, podían ser más sensibles a las posiciones de la comunidad. Ello se reforzaría cuando entrara en vigencia la reforma constitucional introducida por la Ley $N^{\circ} 20.390$ en octubre de 2009 que establece la elección directa por sufragio universal de los consejeros regionales.

Sin embargo, el legislador de la Ley No 20.417 eliminó a los consejeros regionales de la Comisión de Evaluación que reemplaza a la COREMA, según el artículo 86 LBGMA., de modo que la voz que -en teoría- representaba a la comunidad regional fue excluida. Más allá de las razones para esta exclusión, lo cierto es que en materia de participación de la comunidad, la reforma constituye un retroceso en esta parte, dado que se optó por eliminar un componente social en la decisión ${ }^{91}$.

g) Falta de regulación de las compensaciones anteriores a la "rca." Como última cuestión se ha criticado que una empresa pague a una comunidad para que ésta permita la realización de un proyecto ${ }^{92}$. La existencia de compensaciones, si bien puede ser considerada positiva desde la óptica de la justicia ambiental en su vertiente distributiva (en cuanto a la distribución de las cargas o externalidades ambientales), los reparos vienen

${ }^{90}$ En el Derecho comparado los plazos son semejantes. En Alemania, por ejemplo, el plazo es también de sesenta días. En Italia, en tanto, el plazo es de 30 días. Leme, Paulo, cit. (n. 11), pp. 186 y 268.

${ }^{91} \mathrm{La}$ exclusión fue compensada de alguna forma en el artículo 8 inciso 3 LBGMA. que, en el procedimiento de evaluación de impacto ambiental, exige informe del Gobierno Regional y del municipio respecto de la compatibilidad territorial del proyecto.

${ }^{92}$ Liberona, Flavia, ponencia en el Segundo Seminario sobre la Reforma a la Institucionalidad Ambiental. Perspectivas desde la Sociedad Civil, en Hervé, Dominique - Guiloff, Matías - PÉrez, Raimundo (editores), Reforma a la institucionalidad ambiental. Antecedentes y fundamentos (Santiago, Universidad Diego Portales 2010), p. 119. 
dados fundamentalmente por el lado de la protección del entorno ${ }^{93}$. En tal sentido, está el riesgo que una comunidad acepte una interesante compensación no necesariamente ambiental (pensemos, por ejemplo, en la construcción de un parque de diversiones) a cambio de no presentar observaciones ni oponerse de forma alguna a un proyecto que puede resultar lesivo para la flora y fauna del área en que se emplaza. Tampoco es impensado que se produzca una compensación directamente en dinero, como no pocas veces ha ocurrido ${ }^{94}$.

Ante esta situación, la reforma introduce el artículo 13 bis que impone a los proponentes el deber de informar a la autoridad ambiental si han establecido negociaciones con los interesados con el objeto de acordar medidas de compensación o mitigación ambiental. En el evento de existir acuerdos, la norma dispone que éstos no son vinculantes para la calificación. Si bien esto puede considerarse un avance, no es significativo dado que no limita ni encausa las posibilidades de esta clase de acuerdos.

Entre las alternativas de solución a la situación en referencia, se ha propuesto prohibir toda negociación y compensación anterior a la aprobación del proyecto y, una vez que ésta haya tenido lugar, que la Administración asuma el rol de velar porque la compensación esté relacionada con los impactos del proyecto y no con cuestiones diversas, como sería la compra de taxis a los pescadores o de "poleras" a los clubes de fútbol95. Una solución propuesta por el Ejecutivo en la Administración Bachelet en enero de 2009, era establecer por ley un aporte obligatorio que las generadoras de energía eléctrica debían hacer a las comunidades afectadas por la instalación de las centrales. El proyecto pretendía establecer una compensación monetaria a las comunas donde se instalaran las plantas que tuvieran una producción igual o superior a $200 \mathrm{MW}$, fijándose un pago de 270 UTM por megawatt que era descontable de impuestos. Así, una central termoeléctrica de 500

${ }^{93}$ Además de otros reparos relativos a la mercantilización de la participación, la degradación de la ciudadanía, el fomento del individualismo y la despreocupación por las generaciones futuras, etcétera.

${ }^{94} \mathrm{Tal}$ es el caso de la negociación entre Celulosa Arauco y el Sindicato de Pescadores de Licantén. La referida empresa ofreció pagar al Sindicato la suma de seis millones de pesos durante quince meses por cada pescador, a objeto de que la asociación claudicara en su oposición a la instalación de un ducto para descargar residuos industriales al mar. El presidente del Sindicato de Pescadores de Licantén, entidad que aceptó la compensación, señaló: "Como está la situación, los pescadores necesitan plata hoy día y con un juicio van a conseguir plata en dos años con suerte", y refiriéndose a las organizaciones que no aceptaron la negociación -como el Sindicato Mar Brava de Caleta Duao-, expresó: "Ellos con suerte van a recibir algo en dos años". Todo en La Nación, 21 de junio de 2007.

${ }^{95}$ Liberona, Flavia, cit. (n. 92), p. 120. 
MW pagaría alrededor de diez millones de dólares por este concepto. A la iniciativa podían formularse las mismas críticas que respecto de toda compensación, pero particularmente el que el pago fuera descontable de impuestos, pues quien estaría en definitiva compensando sería el Estado. Según informaciones de prensa, el Gobierno del Presidente Piñera habría desistido del referido proyecto ${ }^{96}$.

\section{Conclusiones}

Producto de la naturaleza común del entorno y la universalidad de su afectación, el Derecho ambiental reconoce diversas modalidades de participación de la ciudadanía en los instrumentos de gestión ambiental. En el procedimiento de evaluación de impacto ambiental es posible distinguir dos ámbitos diversos en que se reconoce la intervención de la ciudadanía: por una parte, la participación que atribuye la LBGMA. y que se traduce en el derecho que se confiere a cualquier persona a acceder a la información ambiental, formular observaciones y a recibir respuesta fundada de éstas y, por la otra, la facultad que la LBPA. otorga a aquellas personas en quienes concurre la condición de interesados (por verse afectados con la decisión del procedimiento) de formular sus alegaciones en el curso del procedimiento $\mathrm{y}$, en general, de ejercer el denominado derecho de audiencia.

En el primero de estos estatutos (derechos de participación e información establecidos por la LBGMA.) la reforma introducida en enero de 2010 por la Ley No 20.417 supone una expansión tanto del derecho de acceso a la información (ahora se reconoce a toda persona en armonía con las disposiciones de la LAIP. y se amplían los medios de difusión del procedimiento) como de la garantía de participación. Según se indicó, el derecho de acceso a la información ambiental constituye el sustrato para una participación fundada, a tal punto que sin él, los demás derechos de participación y acceso a la justicia ambiental serán poco efectivos ${ }^{97}$. Respecto de la garantía de participación, el cuerpo legal precitado amplía la titularidad del derecho a formular observaciones (reconociéndose también a toda persona natural o jurídica, con independencia de si se trata de una organización ciudadana y si la persona es o no afectada por el proyecto). Asimismo, la Ley № 20.417 se encarga de subsanar parte importante de los defectos que contenía la LBGMA. en su versión original; entre ellas, se extiende la participación a los proyectos sometidos al "seia" mediante "dia." cuando generen cargas

${ }^{96}$ La Tercera, 23 de diciembre de 2010.

${ }^{97}$ Stookes, Paul, A Practical Approach to Environmental Law (Oxford, Oxford University Press 2005), pp. 33-34. 
ambientales, se consulta la apertura de una nueva etapa de participación ante modificaciones sustanciales del proyecto, se altera la redacción sustituyéndose la ponderación de las observaciones por su consideración y pronunciamiento en un acto trámite del procedimiento, y se reemplaza el recurso especial de reclamación cuando las observaciones no son consideradas por el recurso administrativo especial, de cuya resolución puede reclamarse al Tribunal Ambiental, entre otras modificaciones.

Adicionalmente a este estatuto de participación regulado en la LBGMA., se encuentra el conjunto de facultades que se reconocen a los interesados por la integración de las disposiciones de la LBPA. Respecto de éstas, especial importancia cobran en el procedimiento del "seia" los principios conclusivo, de inexcusabilidad, contradictoriedad, imparcialidad, impugnabilidad y publicidad y transparencia. En el mismo sentido, deben considerarse los derechos que el artículo 17 de dicho cuerpo normativo reconoce a las personas en sus relaciones con la Administración y, en particular, la facultad de los interesados de deducir alegaciones que deben ser tenidas en cuenta por la Administración, como también los deberes de coherencia y motivación de los actos administrativos, normativa plenamente aplicable en la materia por no existir disposiciones en sentido diverso en la LBGMA. (además la naturaleza del procedimiento es perfectamente compatible con las disposición básicas).

A pesar del avance que representa la reforma a la institucionalidad ambiental en este ámbito, se mantiene un cúmulo considerable de aspectos deficientes que no han sido abordados por la modificación legislativa. No obstante, parte importante de las deficiencias en materia de participación ciudadana pueden subsanarse en la práctica administrativa haciendo aplicación de las disposiciones supletorias contenidas en la LBPA., según se ha señalado a lo largo de este trabajo. En este sentido debe avanzarse para aprovechar las potencialidades de la participación de la ciudadanía, en especial, en su rol de prevención de conflictos ambientales, sin perjuicio de promoverse los cambios legislativos que sean necesarios hacia el futuro.

\section{BIBLIOGRAFÍA}

Andaluz, Carlos, Manual de Derecho Ambiental (Lima, Proterra, 2006).

Astorga, Eduardo, Derecho Ambiental Chileno (Santiago, LexisNexis, 2007).

Astorga, Eduardo, Sistema de evaluación de impacto ambiental. régimen jurídico. En especial aplicado a la actividad minera (Santiago, Editorial Jurídica ConoSur, 2000). Bell, Stuart y MacGillivray, Dondald, Environmental Law (Oxford, Oxford University Press, 2006).

Bermúdez, Jorge - Mirosevic, Camilo, El acceso a la información pública como base para el control social y la protección del patrimonio Público, en Revista de Derecho de la Pontificia Universidad Católica de Valparaiso, 31 (Valparaíso, 2008). 
BERMÚDEZ, Jorge, Función y tipología del procedimiento administrativo, en VV. AA., Acto y procedimiento administrativo. Actas de las Segundas Jornadas de Derecho Administrativo (Valparaíso, Ediciones Universitarias de Valparaíso, 2005).

Bermúdez, Jorge, Fundamentos de Derecho ambiental (Valparaíso, Ediciones Universitarias de Valparaíso, 2007).

Cierco, Cesar, La nueva regulación del derecho de audiencia en los procedimientos administrativos comunitarios vinculados a la protección de la competencia, en Revista de Administración Pública, 155 (Madrid, Centro de Estudios Políticos y Constitucionales, 2001).

Colil, Martín, Análisis de la estructura del sistema de evaluación de impacto ambiental (tesis para optar al grado de Magíster en Gestión y Planificación Ambiental, Universidad de Chile, Santiago, 2003).

CONAMA, El desafio del medio ambiente en Chile (Santiago, 2007).

Del FÁvero, Gabriel - Katz, Ricardo, Resultados y consecuencias del sistema chileno de evaluación de impacto ambiental ("seia."), en Estudio Públicos, 73 (Santiago, verano de 1999).

Del FÁvero, Gabriel, Ley sobre bases generales del medio ambiente, en Estudios Públicos, 54 (Santiago, otoño de 1994).

Dieguez, Marcia - Cureau, Sandra, Direito ambiental (Rio de Janeiro, Elsevier, 2008).

DinamarCa, Jaime, Evaluación de impacto ambiental. Análisis del reglamento actualizado (Santiago, LexisNexis, 2003).

Entrena Cuesta, Rafael, Curso de Derecho administrativo (Madrid, Tecnos, 1995).

Fernández, Pedro, Manual de Derecho ambiental chileno (Santiago, Editorial Jurídica de Chile, 2004).

Fundación Terram, Balance ambiental. 2008 (Santiago, 2008).

Funk, William - SeAmon, Richard, Administrative Law (New York, Aspen, 2006).

GARrido Falla, Fernando, Tratado de Derecho administrativo (4a edición, Institutos de Estudios Políticos (Madrid, 1966).

GuZmán, Rodrigo, La regulación constitucional del ambiente en Chile. Aspectos sustantivos $y$ adjetivos (Santiago, LexisNexis, 2005).

Hervé, Dominique, El desarrollo sostenible y la justicia ambiental en la Ley 19.300 y en el Proyecto de reforma a la institucionalidad ambiental, en Hervé, Dominique - GuILOFF, Matías - PÉREz, Raimundo (editores), Reforma a la institucionalidad ambiental. Antecedentes y fundamentos (Santiago, Universidad Diego Portales, 2010).

Kittsteiner, Enrique, Derecho ambiental (Santiago, Aremi, 2004).

Leme, Paulo, Direito ambiental brasileiro (Sao Paulo, Malheiros, 2010).

Liberona, Flavia, ponencia en el Segundo Seminario sobre la Reforma a la Institucionalidad Ambiental. Perspectivas desde la Sociedad Civil, en Hervé, Dominique - GuILOFF, Matías - PÉREZ, Raimundo (editores), Reforma a la institucionalidad ambiental. Antecedentes y fundamentos (Santiago, Universidad Diego Portales, 2010).

Meunier, Pamela, La participación ciudadana en el sistema de evaluación de impacto ambiental chileno, en VV. AA., Prevención y solución de conflictos ambientales: Vias administrativas, jurisdiccionales y alternativas. Actas de las Segundas Jornadas de Derecho Ambiental (Santiago, LexisNexis, 2004).

Moreno, Carlos, Participación ciudadana en la Ley $N^{\circ} 19.300$, sobre Bases generales del medio ambiente (Santiago, LexisNexis, 2004). 
Padilla, Eduardo, Lecciones de Derecho ambiental (Santa Fe de Bogotá, Leyes, 2000). 89

Royo Villanova, Segismundo, El procedimiento administrativo como garantía juridica, en Revista de Estudios Politicos, 48 (Madrid, Centro de Estudios Políticos y Constitucionales, 1949).

Santamaría Pastor, Alfonso, Principios de Derecho administrativo (Madrid, Centro de Estudios Ramón Areces, 2002).

Somanathan, E., Effects of Information on Environmental Quality in Developing Countries, en Review of Environmental Economics and Policy, Vol.4 (Oxford, verano de 2010) 2.

Stookes, Paul, A Practical Approach to Environmental Law (Oxford, Oxford University Press, 2005).

Zanella, María Sylvia, Direito Administrativo (23ª edición, Sao Paulo, Atlas, 2010). 
